\title{
PERFORMANCE OF SILICA-NANO-PARTICLES ON THE PHYSICOCHEMICAL, AND MICROSCOPIC CHARACTERISTICS OF BLENDED AND COMPOSITE CEMENT
}

\author{
MOHAMED HEIKAL*, IVON M. HELMY**, SHEREEN AWAD***, "NOHA S. IBRAHIM*** \\ *Chemistry Department, Faculty of Science, Benha University, Benha, Egypt \\ **Chemistry Department, Faculty of Science, Zagazig University, Zagazig, Egypt \\ ***Faculty of Engineering, Benha University, Benha, Egypt \\ "E-mail: noha.mlijy@bhit.bu.edu.eg
}

Submitted January 20, 2020; accepted March 12, 2020

\begin{abstract}
Keywords: Silica-nano-particles (SNP); Microscopic characteristics; Gel/space ratio; Blended, composite cement
The impact of silica-nano-particles (SNP) onto the physicochemical and microscopic characteristics of composite-cements containing 40 - 60 mass \% fly-ash (FA), and/or granulated-slag (GS) were studied. The physico-mechanical and microscopiccharacteristics of the composite cement-pastes were enhanced by the replacement of 4 mass\% SNP, especially the earlystrength enhancement. The behaviour of the hydration-kinetics was studied from one day up to 360 days. The consistency $(W / C)$ ratio, setting times (STS), compressive strength (CS), total porosity, (TP), bulk density (BD), chemically combined water (Wn), free lime (FL) and gel/space ratio $(X)$ were determined. The behaviour of SNP was proven by XRD, DTA, and SEM techniques. The 4 mass \% SNP improves the characteristics and microscopic hydration behaviour of the inspected blended and composite cements matrices in the existence of FA and GS. SNP have a positive effect on the behaviour of composite cement pastes, it diminished the setting times and improved the compressive strength and gel/space ratio. The SEM micrographs showed the formation of a denser and finer structure of a CSH hydrated gel with a marked reduction in the total porosity of the hardened-cement paste to form a nano-crystalline close textured structure, which is answerable for the strength properties. It was recommended that the composite cement containing 36 mass \% OPC (ordinary Portland cement) + 40 mass $\%$ FA +40 mass $\%$ GS +4 mass $\%$ SNP, an E4 mix, which is the suitable optimum mix composition, showed a dense compact structure mainly-composed of a nano-crystalline close-textured-matrix with a remarkable decrease in the total porosity of the hardened blended and composite cement matrices having a higher compressive strength.
\end{abstract}

\section{INTRODUCTION}

In the future, it will not be possible to pursue technological goals without giving equal importance to public interest issues in preserving the ecological balance on the planet Earth. Large amounts by-products and industrial waste are generated every year in the chemical and agricultural industries namely, fly-ash (FA), granulated-slag (GS), and microsilica (MS), these wastes and by-products have the dual problem of disposal and being a health hazard. Fly-ash produced as a by-product from coal combustion in large power stations. Granulated-slag (GS) and microsilica (MS) are by-products of electrical arc furnace production of silicon and or its alloys [1, 2]. FA, GS, and MS are used in structural concrete materials as partial replacements of approximately $10-50 \%$ of OPC, which enhances the durability of the produced concrete. Indeed, this process reduces the release of greenhouse-gases and saves energy, meanwhile it reduces the accumulating stockpiles of the waste and by-products which is an environmental concern.
Nanotechnology (NT) and nanomaterials (NMs) have attracted the most considerable-scientific topic attention up to now, due to overpopulation and an increase in the required housing, the new potential uses of nanoparticles (NPS), and also, due to their properties on an ultra-fine level which have led to changes in the concrete world [3]. NMs were used either as a replacement percentage level of OPC and or as an additive in OPC pastes, producing an ecological-profile enhancing the realisation of construction concrete [4-7]. NMs show great reactivity due to their high purities and specific surface areas as well as their high-performance engineering properties, which are different than traditional building materials. They act as fillers, and active centres promoting the reaction of the cement hydration; they aid in the production of homogeneous $\mathrm{C}-\mathrm{S}-\mathrm{H}$ clusters, small-sized $\mathrm{CH}$ crystals and improve the interfacial transition zone-structure (ITZ) [8].

The most popular NMs used in OPC concrete products are silica-nano-particles (SNP), nano-titanium oxide (NT), nano-alumina (NA), nano-iron oxide (NF), nano-zirconium oxide (NZ) and nano-carbon-tubes 
(NCTs) [9-17]. SNP act as the special and highly pozzolanic-activity role and seeding centres promoting hydrated products and improving the microstructure [18-22]. SNP diminish the setting times, enhance the liberation the heat results from the hydration, and improve the rheological characteristics of building materials $[23,24]$. SNP enhance the mechanical and durability characteristics, decrease the porosity and improve the different aspects [23-28]. Some studied papers showed the performance of SNP as NMs in cement-building materials [29, 30]. SNP react with liberated calcium hydroxide $(\mathrm{CH})$ from the OPC hydration to produce excessive-amounts of a $\mathrm{C}-\mathrm{S}-\mathrm{H}$ building close matrix; hence the compressive strength was improved. The improvement in cement building materials in the presence of SNP is attributed to the large surface area, the filling behaviour and pozzolanic action, which speeds up the rate of the hydration reaction and kinetics [31, 32]. Wang [33] investigated the influence of NMs on the characteristics of building binders. The obtained results showed that NMs shorten the setting times, accelerate the hydration of cement during the first $24 \mathrm{hrs}$, increase the rheology of the pastes after $1 \mathrm{~h}$. The influence of SNP on the strength and microstructure of cement pastes has been demonstrated [34]. The improvement in the compressive strength of cement pastes were $33.2 \%$ and $18.5 \%$ at 3 days and 28 days, respectively. El-Didamony, et al. [35] investigated the combined behaviour of both FA and SNP on composite cements. SNP represent an intensifying agent for improving the behaviour of FA in the cement and they activate the formation of excessive hydrated products from the pozzolanic action of the siliceous and aluminous contents of the FA with the lime compared to the behaviour of the FA in the cement. Roychand, et al. [36] explained the results obtained from the inclusion of $5 \%$ SNP to combined supplementary cementitious materials (SCM) namely, FA and GS mixtures in the presence of lime to achieve a non-cement eco-friendly composite without heat treatment. SNP enhance the pozzolanic reaction of FA, and GS to form calcium silicate hydrate $(\mathrm{CSH})$, calcium aluminate hydrate $(\mathrm{CAH})$, and calcium aluminosilicate $(\mathrm{CASH})$ hydrated gel. Ehsani, et al. [37] investigated the action of SNP on the performance of cement and eco-friendly alkaline activated systems having FA and GS. Slump loss, compressive strength, hydration reaction kinetics, porosity, and gel structure were also analysed for the eco-friendly composite [38]. Biricika and Sarier [39] studied the performance of cement impregnated with
SNP, MS, and FA. The SNP cement's compressive strength was higher than that of cement with MS and FA, due to the extensive active area of the SNP. The SNP particles promote the reaction of $\mathrm{C}_{3} \mathrm{~S}$ and $\beta-\mathrm{C}_{2} \mathrm{~S}$ phases with water to induce pozzolanic reactivity with the formation of the CSH phase.

This work studied the synergetic action of SNP and supplementary cementitious materials (fly-ash and granulated-slag) on the physicochemical, microstructure, and the hydration reaction of a composite cement.

Various cement mixtures having 40 - 60 mass \% FA, and/or GS in the presence and absence of SP were studied using XRD, DTA, and SEM techniques. Along with the consistency, STs, BD, and CS were also analysed. The results obtained confirmed the synergetic behaviour of the SNP, fly-ash and granulated-slag up to 360 days.

\section{EXPERIMENTAL}

Ordinary Portland cement (OPC), granulated slag (GS), Fly-ash (FA), silica-nano-particles (SNP) constituted the starting materials used in this study. The OPC was obtained from the Suze Portland-Cement Company and the granulated slag was provided from the Iron-Steel-Company, Helwan, Egypt. The FA was obtained from the Sika-Chemical Company for Building Materials, Egypt. The surface area determined from the Blaine test of OPC, FA and GS were 3080, 3570 and $3980 \mathrm{~cm}^{2} \cdot \mathrm{g}^{-1}$, respectively. The SNP used in this work was supplied from the Nanotechnology Materials Lab., Building and Housing Research Centre, Cairo, Egypt. The particle size, surface area and purity of the SNP are $\sim 18 \mathrm{~nm}, 49.88 \mathrm{~m}^{2} \cdot \mathrm{g}^{-1}$ and $98.99 \%$, respectively. The superplasticiser-based-polycarboxylate (SP) was supplied from the Sika Construction Chemicals Company. The nature of the FA, GS and SNP were measured using an XRD-technique as shown in Figure 1. Figure 2 represents the TEM of the SNP. The chemical analyses of the SNP, FA, GS, and OPC were determined by XRF spectrometry as shown in Table 1.

The OPC, FA, and GS anhydrous blends were intermixed in a ball mill mixer as shown in Table 2 . To avoid the coagulation of the SNP, the mixing was performed in a rotary mixer as shown; the SNP was mixed with the suitable $\mathrm{W} / \mathrm{C}$ ratio (standard-consistency as given in Table 2); first, mixing at $\sim 120 \mathrm{rpm}$ up to one min; the anhydrous blends (OPC, GS and/or FA) were mixed to full homogenisation at $90 \mathrm{rpm}$ up to $2 \mathrm{~min}$; the

Table 1. The chemical analyses of the materials used (mass \%).

\begin{tabular}{lcrrrrrrrrr}
\hline & $\mathrm{Fe}_{2} \mathrm{O}_{3}$ & $\mathrm{Al}_{2} \mathrm{O}_{3}$ & $\mathrm{SiO}_{2}$ & $\mathrm{CaO}$ & $\mathrm{Na}_{2} \mathrm{O}$ & $\mathrm{K}_{2} \mathrm{O}$ & $\mathrm{MgO}$ & $\mathrm{SO}_{3}$ & L.O.I & Total \\
\hline OPC & 5.05 & 3.58 & 21.30 & 63.48 & 0.26 & 0.22 & 1.39 & 2.05 & 2.57 & 99.90 \\
GS & 0.59 & 9.97 & 43.21 & 35.96 & 0.79 & 0.67 & 5.43 & 1.37 & 1.98 & 99.97 \\
FA & 5.4 & 26.54 & 63.10 & 2.33 & 0.85 & 0.52 & 0.01 & 0.09 & 0.8 & 99.64 \\
SNP & 0.01 & 0.03 & 98.59 & 0.01 & 0.3 & 0.04 & 0.01 & 0.3 & 0.01 & 100 \\
\hline
\end{tabular}


SP was inserted into the homogenised rotary mixer at $120 \mathrm{rpm}$ for up to $30 \mathrm{~s}$; then the cement blends were left to rest for $30 \mathrm{~s}$; this was followed by mixing at a speed of $120 \mathrm{rpm}$ for one min. The mixing blends were inserted into $2.54 \times 2.54 \times 2.54 \mathrm{~cm}^{3}$ moulds, then two paste layers were compressed manually, then it was stored in a cabinet of humidity (100\% RH (relative humidity)) at $20 \pm 1{ }^{\circ} \mathrm{C}$ for $24 \mathrm{hrs}$ and then stored underwater for a suitable time (1, 3, 7, 28, 90 and 360 days). The composition mixes are tabulated in Table 2. The consistency and STs of the fresh-mixed blends were monitored according to ASTM: C191 [40]. The hydrated pastes were stopped using a methanol-acetone mixture, and diethyl ether, then dried at $70{ }^{\circ} \mathrm{C}$ for up to $1 \mathrm{~h} \mathrm{[41]}$. The chemically combined water $\left(W_{n}\right)$, free lime (FL) contents can be calculated according

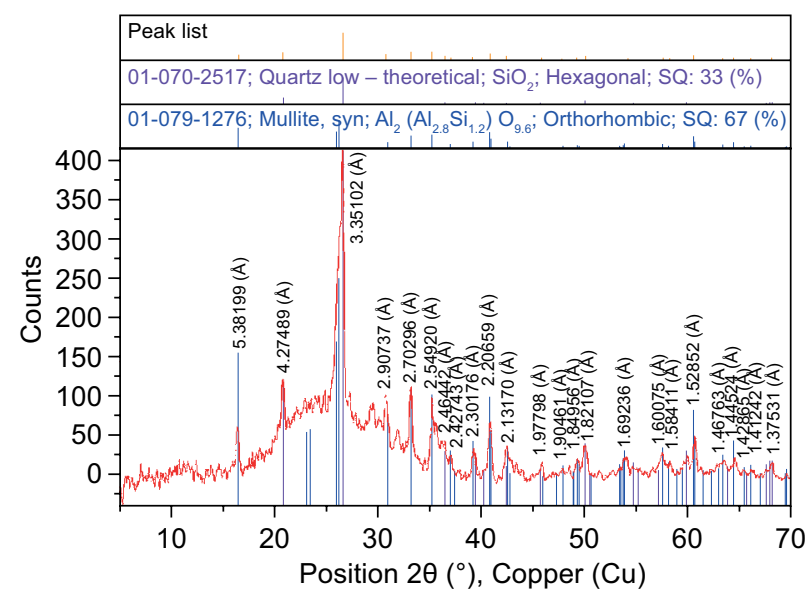

a) FA

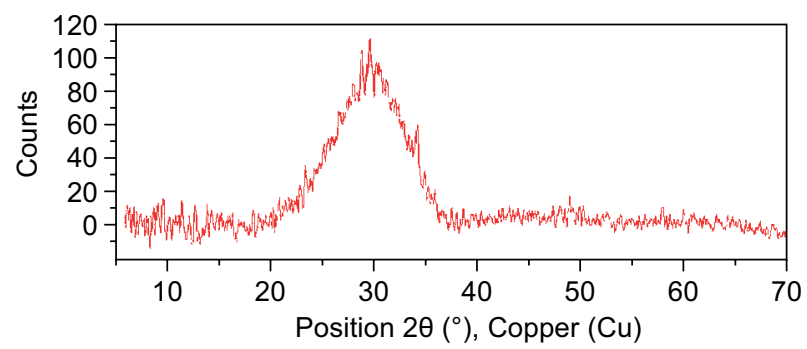

b) GS

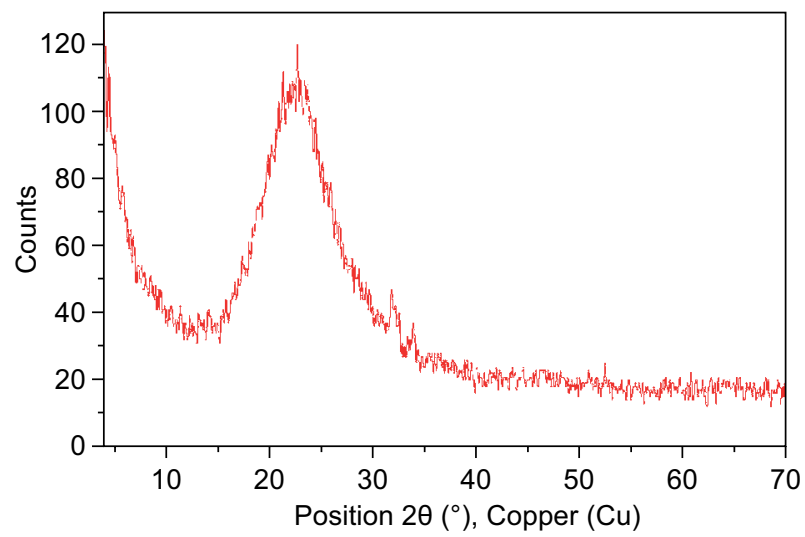

c) $\mathrm{SNP}$

Figure 1. The XRD patterns of the: a) FA; b) GS; c) SNP. to $[41,42]$. The bulk density (BD) was measured before the determination of the compressive strength (CS) [43]. A $600 \mathrm{kN}$ capacity SEIDNER Riedinger compressionmachine was used to determine the compressive strength [44].

For the XRD, a PW 1730 with a Philips X-ray source diffractometer of $\mathrm{Cu} \mathrm{K} \alpha$ radiation $(\lambda=1.5418 \AA)$ was used. The speed of the scan of $2 \theta \mathrm{min}^{-1}$ was between $5^{\circ}-65^{\circ}$. The X-ray tube voltage and the current were at $40 \mathrm{kV}$ and $25 \mathrm{~mA}$, respectively. The analysis of the XRD was performed with computer software that searched for the PDF diffraction data (JCPDA-ICDD), 2001.

The differential thermal gravimetry (TGA/DTG) was carried out by using a Shimadzu DSC-50 thermal analyser at a heating rate of $20{ }^{\circ} \mathrm{C} \cdot \mathrm{min}^{-1}$, the rate flow of nitrogen was $30 \mathrm{~cm}^{3} \cdot \mathrm{min}^{-1}$. The microstructure was investigated by ESEM "Inspect S", FEI Holland, to study the specimen's morphology without any coating.

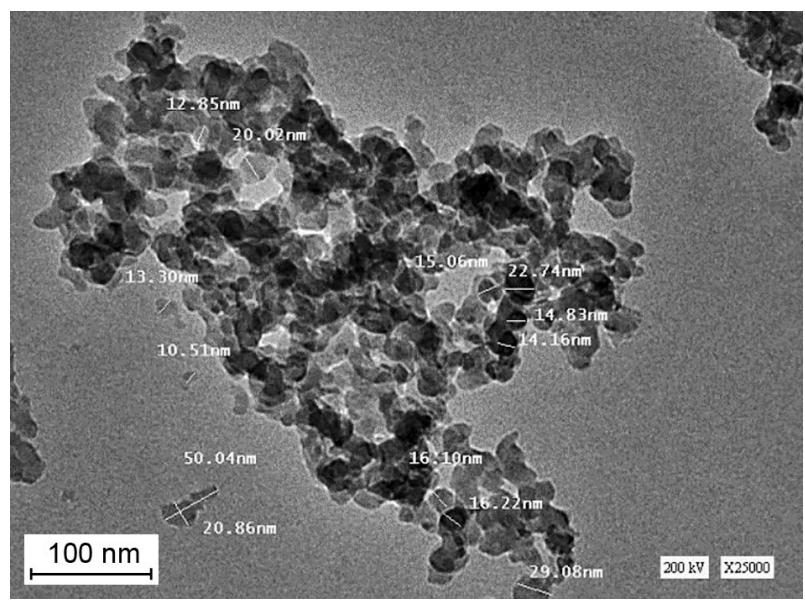

Figure 2. The TEM of the SNP.

\section{RESULTS AND DISCUSSION}

\section{Consistency, and setting times}

The consistency (W/C), and setting times (STs) of the OPC composite pastes containing FA and or GS in a hybrid of 4 mass \% SNP and SP are tabulated in Table 2. The obtained data show that the OPC composite cement pastes containing 4 mass \% SNP need a higher water demand and show shorter setting times (STs) in comparison with the OPC composite cement blends without the SNP, this is due to the high surface area of the SNP [20].

Silica-nano-particles (SNP) react with the liberated $\mathrm{Ca}^{2+}$ available from the hydration reaction of the cement phases with the mixing water, forming an excessive amount of calcium silicate hydrate $(\mathrm{CSH})$, calcium aluminate hydrate $(\mathrm{CAH})$, and calcium aluminosilicate (CASH) hydrated gel. The CSH particles serve as seeding crystals to form more CSH phases later, consequently, the STs are reduced. 
Table 2. The composition of the different mixes (mass \%).

\begin{tabular}{|c|c|c|c|c|c|c|c|c|}
\hline \multirow[t]{2}{*}{ Mix } & \multirow{2}{*}{$\begin{array}{c}\text { OPC } \\
(\%)\end{array}$} & \multirow{2}{*}{$\begin{array}{l}\text { GS } \\
(\%)\end{array}$} & \multirow{2}{*}{$\begin{array}{l}\text { FA } \\
(\%)\end{array}$} & \multirow{2}{*}{$\begin{array}{l}\text { SNP } \\
(\%)\end{array}$} & \multirow{2}{*}{$\begin{array}{l}\text { SP } \\
(\%)\end{array}$} & \multirow{2}{*}{$\begin{array}{c}\text { Consistency } \\
(\%)\end{array}$} & \multicolumn{2}{|c|}{ Setting times } \\
\hline & & & & & & & Initial & Final \\
\hline A1 & 100 & 0 & 0 & 0 & 0 & 25.7 & 200 & 285 \\
\hline $\mathrm{A} 2$ & 100 & 0 & 0 & 0 & 1 & 19.5 & 70 & 260 \\
\hline A3 & 96 & 0 & 0 & 4 & 0 & 32.0 & 120 & 254 \\
\hline A4 & 96 & 0 & 0 & 4 & 1 & 27.7 & 68 & 215 \\
\hline B1 & 60 & 0 & 40 & 0 & 0 & 29.5 & 280 & 400 \\
\hline B2 & 60 & 0 & 40 & 0 & 1 & 20.0 & 190 & 300 \\
\hline B3 & 56 & 0 & 40 & 4 & 0 & 38.7 & 135 & 360 \\
\hline B4 & 56 & 0 & 40 & 4 & 1 & 29.0 & 96 & 250 \\
\hline $\mathrm{C} 1$ & 60 & 40 & 0 & 0 & 0 & 24.5 & 168 & 290 \\
\hline $\mathrm{C} 2$ & 60 & 40 & 0 & 0 & 1 & 17.0 & 98 & 264 \\
\hline $\mathrm{C} 3$ & 56 & 40 & 0 & 4 & 0 & 32.5 & 85 & 256 \\
\hline $\mathrm{C} 4$ & 56 & 40 & 0 & 4 & 1 & 23.0 & 70 & 200 \\
\hline D1 & 60 & 20 & 20 & 0 & 0 & 26.7 & 210 & 300 \\
\hline D2 & 60 & 20 & 20 & 0 & 1 & 18.0 & 105 & 274 \\
\hline D3 & 56 & 20 & 20 & 4 & 0 & 34.3 & 120 & 289 \\
\hline D4 & 56 & 20 & 20 & 4 & 1 & 24.8 & 85 & 220 \\
\hline E1 & 40 & 40 & 20 & 0 & 0 & 26.0 & 220 & 355 \\
\hline E2 & 40 & 40 & 20 & 0 & 1 & 17.5 & 130 & 295 \\
\hline E3 & 36 & 40 & 20 & 4 & 0 & 33.9 & 110 & 280 \\
\hline E4 & 36 & 40 & 20 & 4 & 1 & 24.0 & 80 & 205 \\
\hline
\end{tabular}

The consistency reduced due to the high dispersion of the SP [45], this is attributed to an increase in the fresh pastes fluidity, leading to a remarkable lowering of the $\mathrm{W} / \mathrm{C}$ ratio; therefore, the composite cement pastes in the hybrid of 4 mass \% SNP and SP possess high hydraulic characteristics [46]. The results also showed that the $\mathrm{W} / \mathrm{C}$ ratio and STs of the composite cements containing GS diminished in comparison with OPC-FA composite cement mixes. The FA has a lower activity than the GS at ages less than 28 days (1 day up to 7 days) [47], wherever the FA composite cement pastes require a higher $\mathrm{W} / \mathrm{C}$ ratio and longer STs. From these results, the amount of the $\mathrm{W} / \mathrm{C}$ ratio decreases and the STs elongated by the replacement of the GS with FA is as shown in the D mixes (60\% OPC $+20 \% \mathrm{FA}+20 \% \mathrm{GS})$ or with the addition of FA as shown in the E mixes (40\% OPC $+40 \% \mathrm{GS}+20 \% \mathrm{FA})$, this is mainly attributed to the reduction in the OPC content as shown in Table 2.

\section{Physico-mechanical properties}

\section{Compressive strength}

The effectiveness of the 4 mass \% SNP on the compressive strength (CS) of the composite pastes up to 360 days is represented in Figure 3. The data obtained from Figure 3 represented an increase in the CS with an increase in the curing period for all the hardened pastes, as the persistent formalisation of the successive amounts of calcium silicate hydrates and calcium aluminosilicate hydrates (strength source), these hydrates precipitated within the ready pores to the output of the compact hardened cementitious body [20]. The CS of the composite cement pastes was improved in the composite cement pastes in the presence of the $4 \%$ SNP and FA and or GS; this is due to the fact that SNP manages as a filling component to enhance the nano-structure of the hardened composite cement matrices as well as due to the active high efficient ingredient pozzolana containing highly amorphous particles promoting the reaction with $\mathrm{CH}$ to generate the $\mathrm{CSH}, \mathrm{CAH}$, and $\mathrm{CASH}$ gel, to form the closed and compact nano-structure hardened cement matrices. The results also showed that the values of the CS of the composite cement pastes in conjunction with the SP are higher than the pastes without the SP. The SP decreases the $\mathrm{W} / \mathrm{C}$, hence the initial porosity decreases, facilitating the contact and approaching of highly amorphous SNP particles to the progressive $\mathrm{CH}$ from the hydration reaction of the cement phases to form the excessive amount of hydrated cementitious products (CSH, CAH, and CASH gel).

The CS of the composite cement pastes containing 40 mass \% FA + 4 mass \% SNP, the B4 mix, increase than those of the neat $\mathrm{OPC}$, especially at later age (90 - 360 days). The CS increases with $20 \%, 21 \%$, and $23 \%$ for 28,90 , and 360 days, respectively, than the OPC pastes represented in Figure $3 \mathrm{a}, \mathrm{b}$. On one hand, the CS of the C4 mix increased by $70 \%, 30 \%, 23 \%$, $21 \%, 29 \%$, and $28 \%$ for the specimens cured at 1,3 , $7,28,90$, and 360 days, respectively, than those OPC FA pastes shown in Figure 3b, c [48, 49]. On the other hand, the CS of the FA blended cement pastes decreases; this is assigned to the somewhat pozzolanic activity of the FA particles [50]. The results of the CS of the composite 
cement pastes containing $40 \% \mathrm{OPC}+20 \% \mathrm{FA}+40 \%$ GS $+4 \%$ SNP are higher than the neat OPC by $35 \%$, $14 \%, 7 \%, 5 \%, 12 \%$, and $20 \%$ for the specimens cured at $1,3,7,28,90$, and 360 days, respectively, as shown in Figure $3 \mathrm{a}$, e; but lower than the cement pastes containing $60 \% \mathrm{OPC}+20 \% \mathrm{FA}+20 \% \mathrm{GS}+4 \% \mathrm{SNP}$ as shown in Figure 3e.

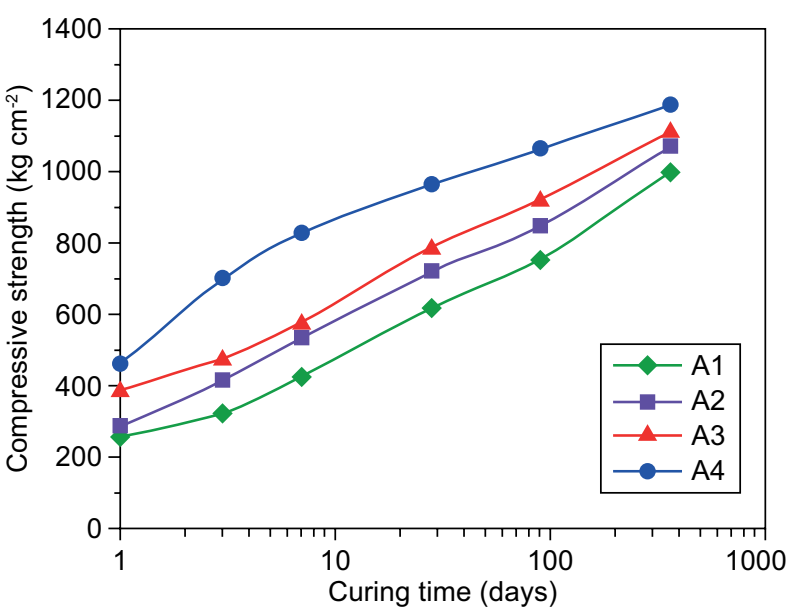

a)

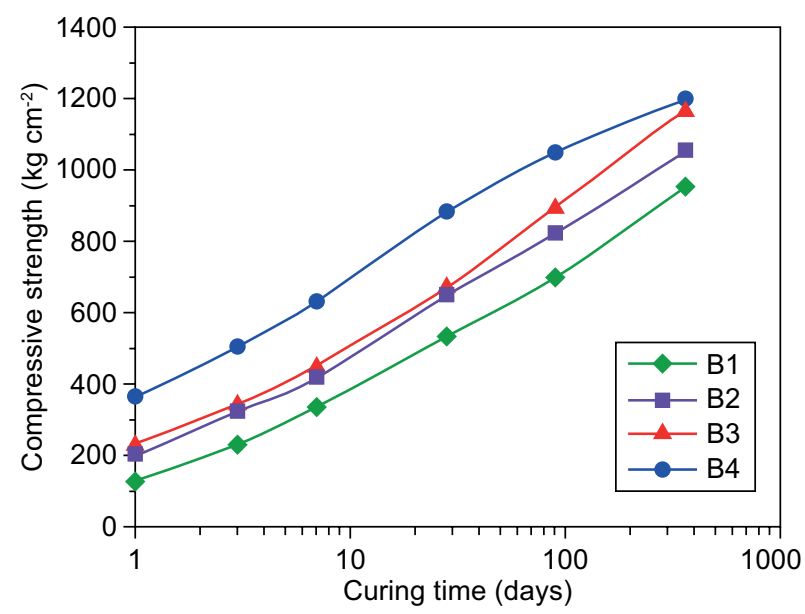

b)

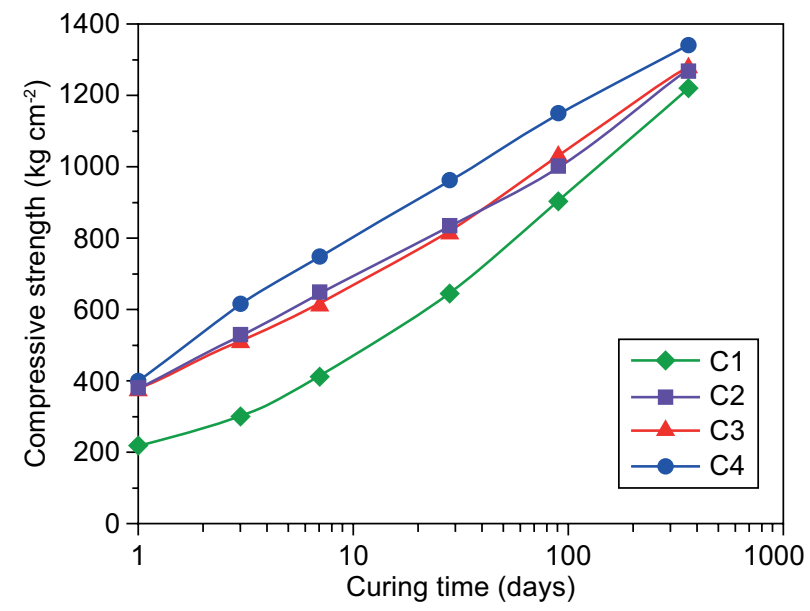

c)

\section{Gel/space ratio}

The gel/space ratio $(X)$ of the OPC-FA-GS pastes with and without the SNP in the hybrid of the SP was graphically represented in Figure 4 . The gel/space ratio was calculated using the data of $W_{n}$ and $W_{n}^{\infty}$ (the combined water when fully hydrated) and the $\mathrm{W} / \mathrm{C}$ ratios. The $X$ values are influenced by the hydration degree, the W/C ratio, and the curing temperature. The $X$ ratio increases with age, attributed to the formulation of the extra amounts of $\mathrm{CSH}, \mathrm{CAH}$ in addition to the CASH products, this tends to increase the $X$ values [51]. The production of the extra amounts of $\mathrm{CSH}, \mathrm{CAH}$ in addition to the $\mathrm{CASH}$ products increases the gel/space ratio; consequently, the $\mathrm{CS}$ of the composite cement pastes enhances. Figure 4 represents the growth in the $X$ values of the OPC-FA-GS composite cement pastes in the hybrid within the SP. The polycarboxylate-based superplasticiser reduces the W/C and TP, which increases the $X$ values [46]. The composites pastes containing the GS and 4 mass \% SNP, the $\mathrm{C} 4$ mixes show a higher value of the gel/space ratio in comparison with the neat OPC by $44 \%, 42 \%, 55 \%$, $58 \%, 56 \%$, and $62 \%$ for the specimens cured at 1,3 , 7,28 , and 90 days, respectively, and higher than the

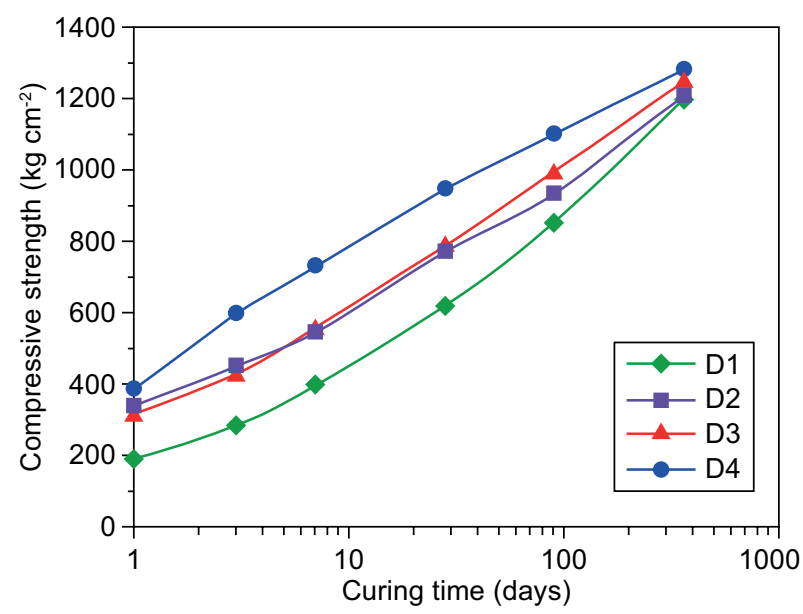

d)

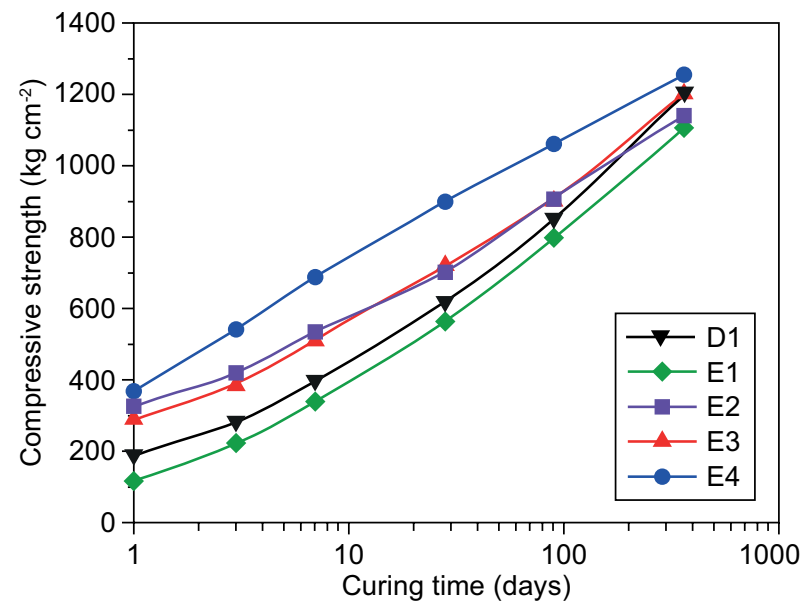

e)

Figure 3. The CS of the pastes with and without $4 \%$ SNP and $1 \%$ SP. 
OPC-FA-SNP composite cement pastes, the B4 mix by $27 \%, 20 \%, 31 \%, 29 \%, 29 \%$, and $30 \%$ for specimens cured at $1,3,7,28$, and 90 days, respectively, as shown in Figure 4a-c. The presence of SNP and GS illustrate a synergetic effect of the performance of the FA to increase the values of the gel/space ratio as well as to enhance the later hydration product as shown in Figure 4d,e.

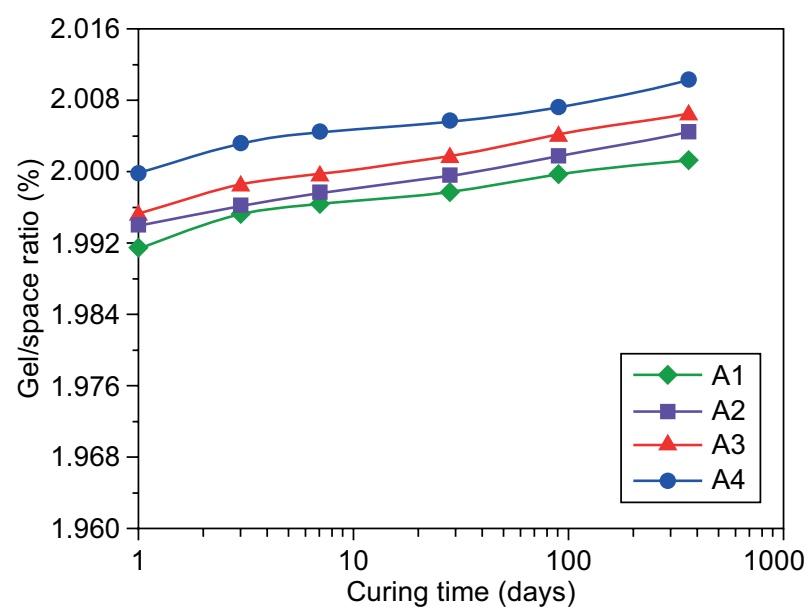

a)

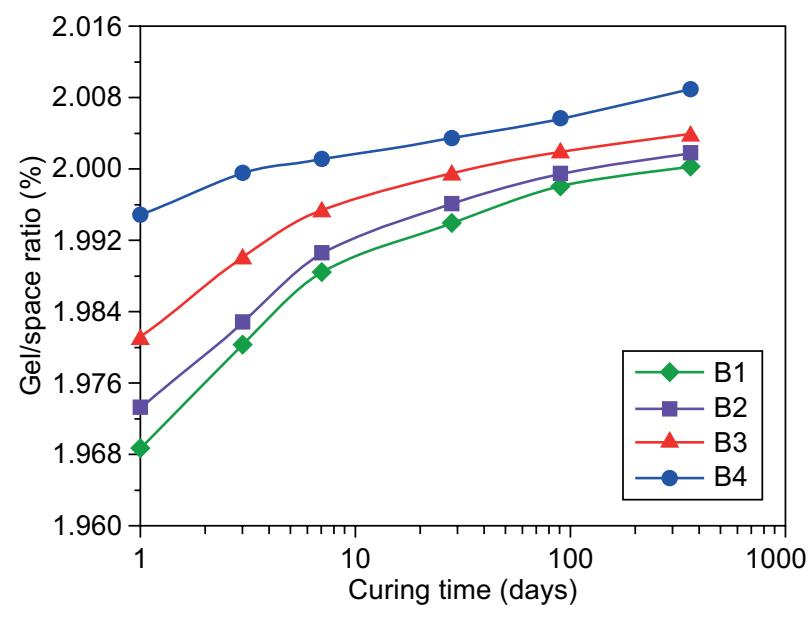

b)

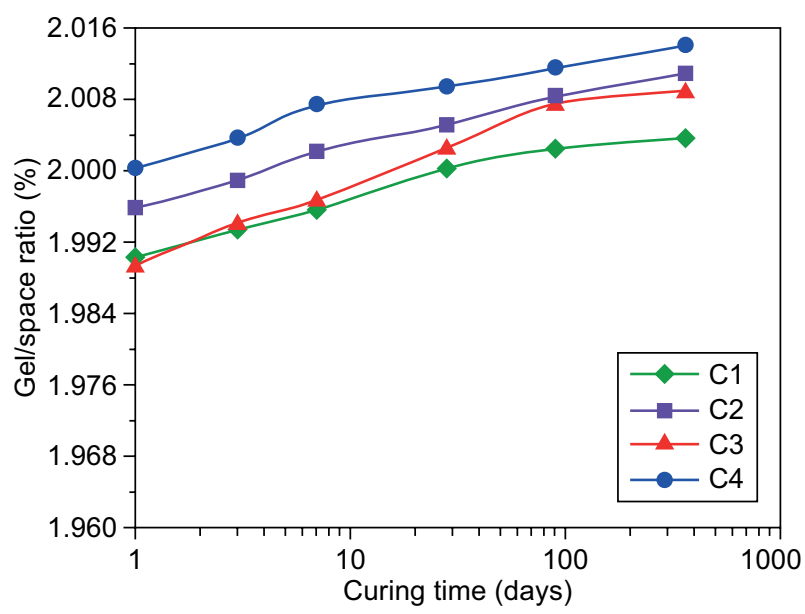

c)

\section{Total porosity}

The variations in the total porosity (TP) of composite cement pastes in the crossbreed of 4 mass $\%$ SNP are presented in Figure 5. An increase in the amounts of the hydrated products means the TP decreases. The results represent the decreasing values of the TP of the composite pastes in the crossbreed of the SNP and SP, which is assigned to the fashioning of extra amounts of calcium silicate, calcium aluminate, and calcium aluminate products, from the action of the pozzolanic activity of the SNP and $\mathrm{CH}$. The SP reduces the W/C ratio and hence the initial porosity and pore volume of the cement specimens decrease facilitating the connection and adjacent particles between the SNP and lime to form $\mathrm{CSH}, \mathrm{CAH}$, and $\mathrm{CASH}$. The values of the TP of the composite cement pastes possess OPC-GS-SNP; the $\mathrm{C} 4$ mix is lower than the other composite cement pastes. By increasing the GS content, the TP increases where the E4 mix has a lower value in the total porosity than the D4 mix, due to the combined effect of the SNP, GS and FA as shown in Figure 5d-e.

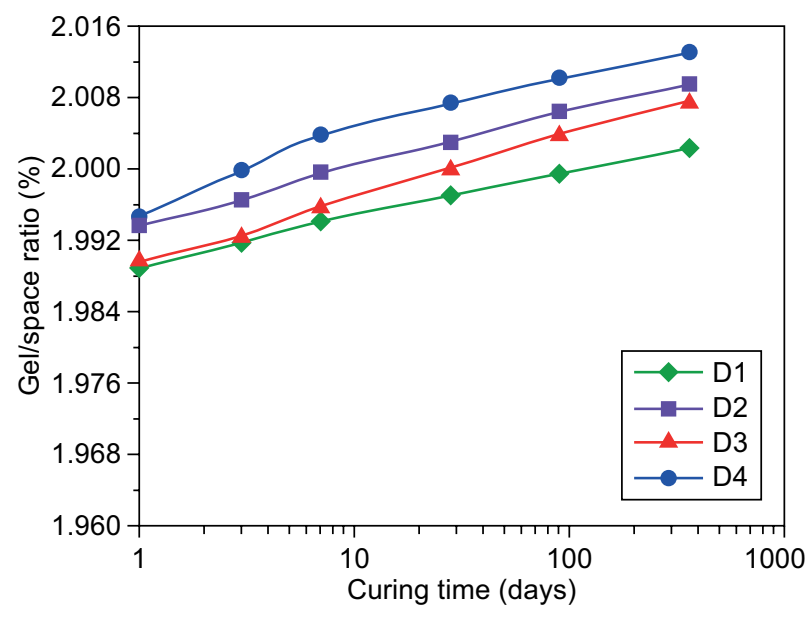

d)

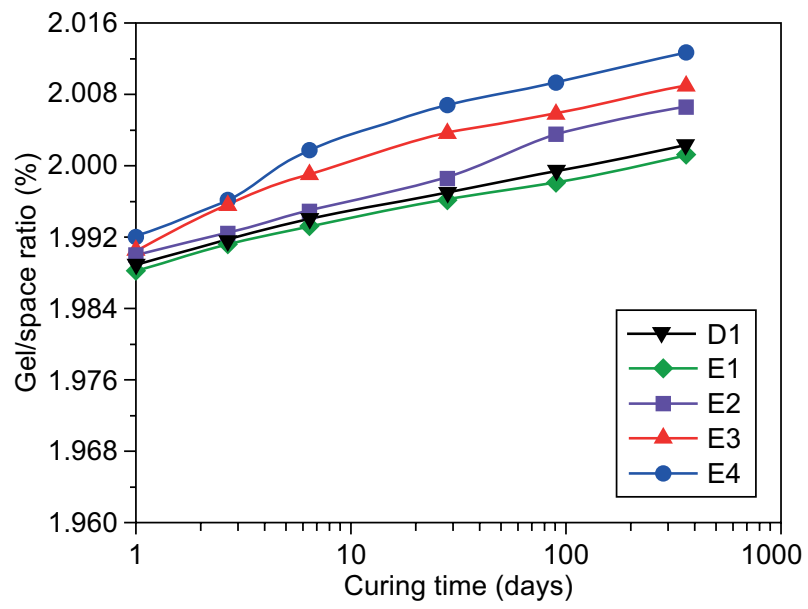

e)

Figure 4 . The gel/space ratio of the pastes containing 4 mass $\%$ SNP. 


\section{Bulk density}

The values of bulk density (BD) of composite-cement-pastes in the hybrid of $4 \%$ SNP and SP cured up to 360-days are depicted in Figure 6. The BD increases with time increasing, due to the continued of the hydration reaction of cement phases in addition to the action of

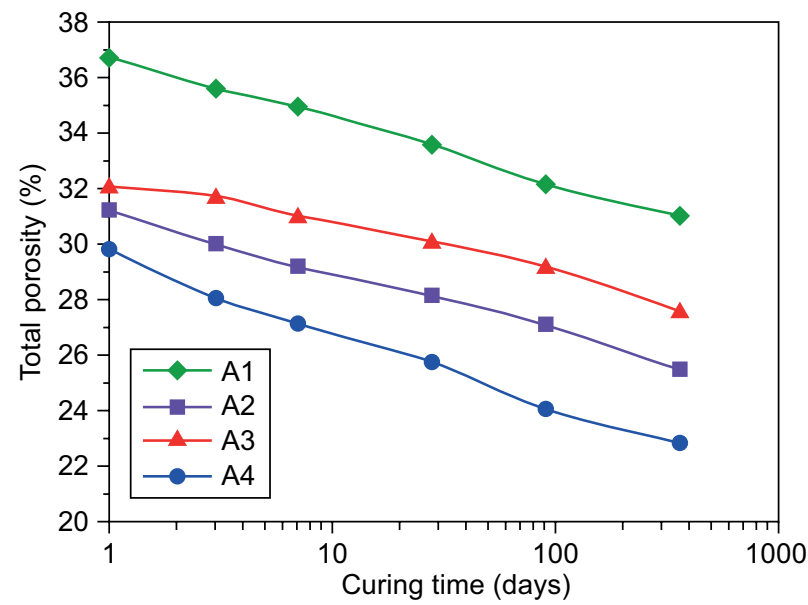

a)

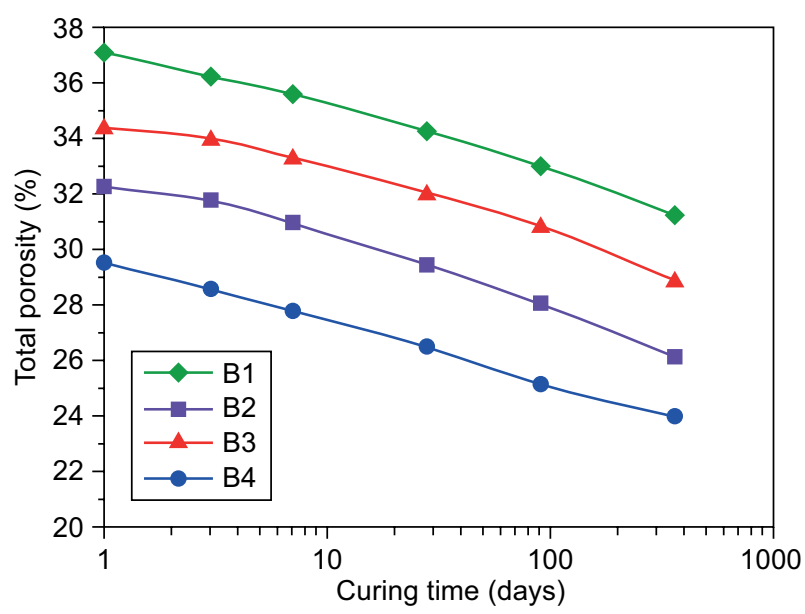

b)

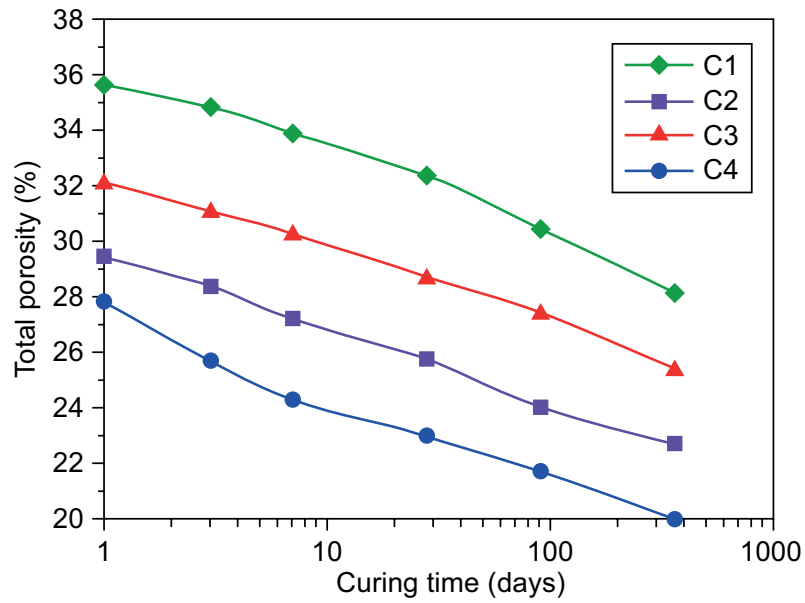

c) the pozzolanic activity of the SNP in the presence of GS and FA, to accumulate excessive amounts of hydrates, which tend to increase the BD and $X$ ratio [51]. The BD of the cement pastes containing SNP is higher than those of the control sample and other mixes without the SNP [20]. The BD shows a higher value in the conjugated SP than those without the SP, because of the decreases in the $\mathrm{W} / \mathrm{C}$ ratio, which increases the mechanical properties. As the W/C decreases, the TP also decreases and the $\mathrm{BD}$ increases. The BD of GS composite cement pastes increase more than the values of the neat OPC, especially at later hydration ages and also the values of the $\mathrm{BD}$ are higher than those of the OPC-FA cement pastes (Figure 6). The results show that with the increase in the GS content, the BD increases as shown in Figure 6e [52]. The SNP present in the cement as the kernel can promote the pozzolanic reaction of the silica and alumina from the GS and FA as well as enhance the hydration of the anhydrous cement. SNP affects the crystallisation of the $\mathrm{CH}$ and the efficiency of the pozzolanic activity reaction.

The results of the physicomechanical properties, namely the $\mathrm{CS}$, gel/space ratio, $\mathrm{TP}$, and $\mathrm{BD}$ are in a good agreement with each other. They show a decrease in the

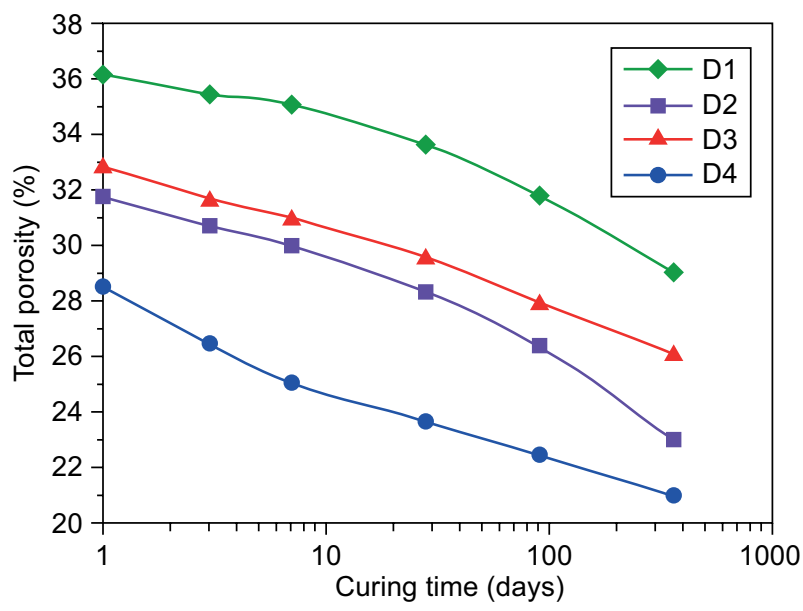

d)

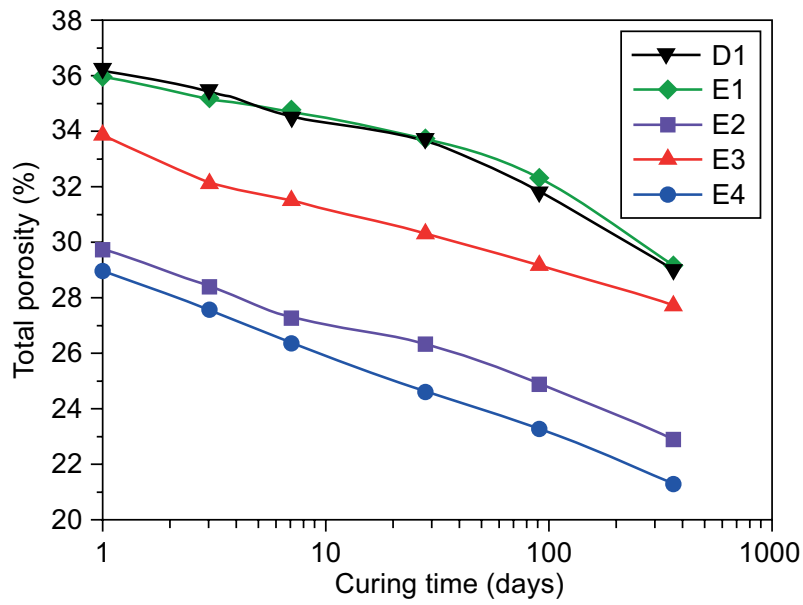

e)

Figure 5. The total porosity of the pastes with and without the 4 mass $\%$ SNP. 
$\mathrm{CS}$, gel/space ratio, TP when the OPC was replaced with 40 mass \% FA, the B mixes, particularly at 1-7 days, but at 90 and 360 days also (later ages), give comparable results with those of the neat OPC pastes. On the one hand, when the OPC was substituted with 40 mass \% GS, the $\mathrm{C}$ mixes, the results of the physicomechanical properties show an increase in the CS, gel/space ratio,

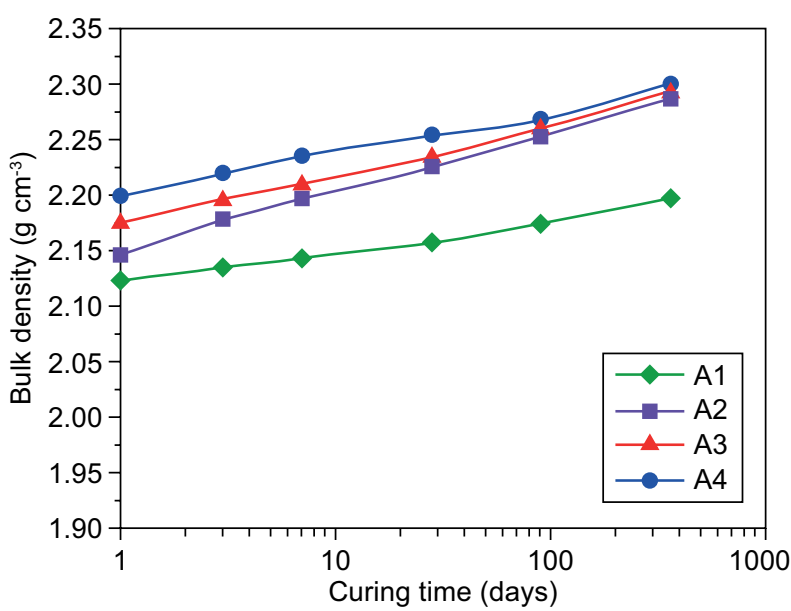

a)

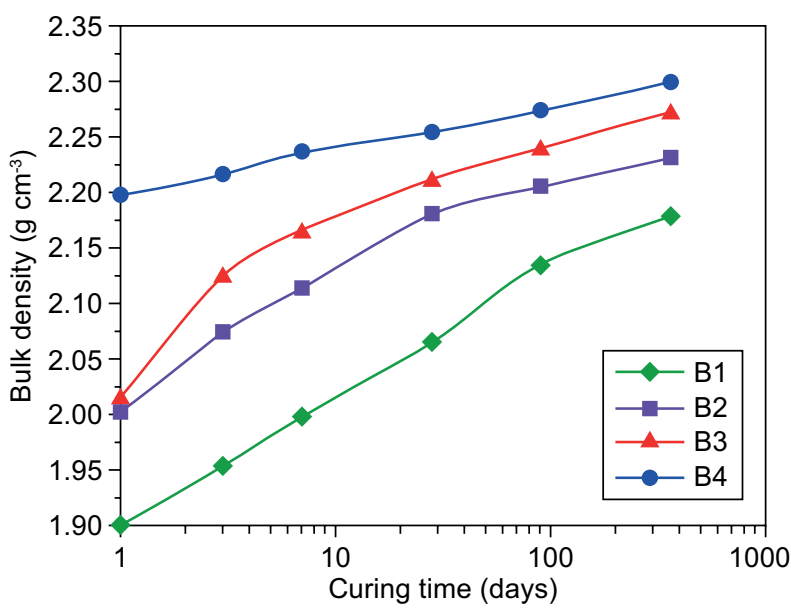

b)

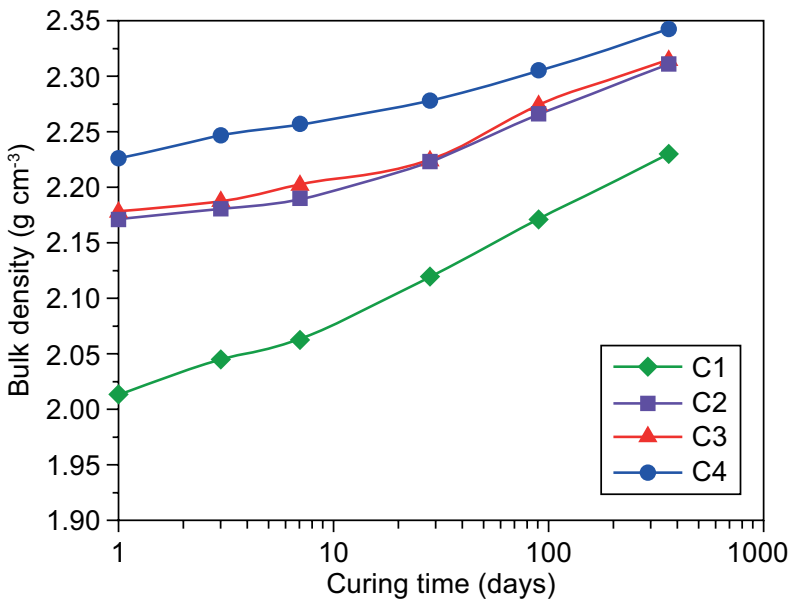

c)
$\mathrm{TP}$, and $\mathrm{BD}$ from 3 days up to 360 days. The replacement of the OPC with 20 mass \% FA + 20 mass $\%$ GS, the $\mathrm{D}$ mixes, the results of the $\mathrm{CS}$, gel/space ratio, TP, and BD show a decrease in their values as shown in the results of the $\mathrm{D}$ mixes. On the other hand, the increase in the replacement of the OPC with 20 mass \% FA + 40 mass \% GS, the E mixes, the results show resettable values with the results of the A mixes, although the OPC was replaced by 20 mass $\% \mathrm{FA}+40$ mass $\% \mathrm{GS}$.

\section{Hydration kinetics}

\section{Chemically combined water contents}

The chemically combined water contents $\left(W_{n}\right)$ of the OPC-FA-GS composite pastes cured up to 360 days are illustrated in Figure 7 . The $W_{n}$ contents give information about the degree of hydration of the cement pastes. The $W_{n}$ increases with an increase in the age; due to the increase in the products formed, to form superior amounts of hydrates, which speed up the filling the pore system in the cement pastes. The results show that the SNP existence in the composite cement pastes have

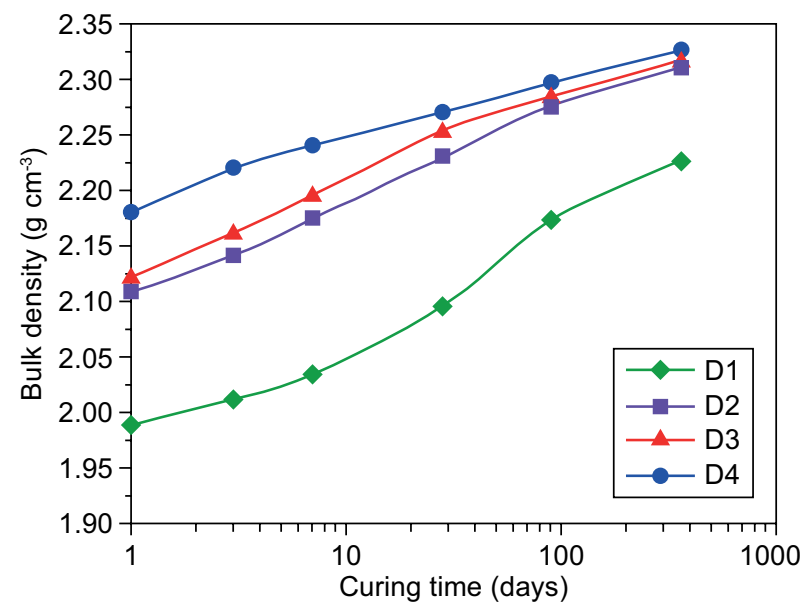

d)

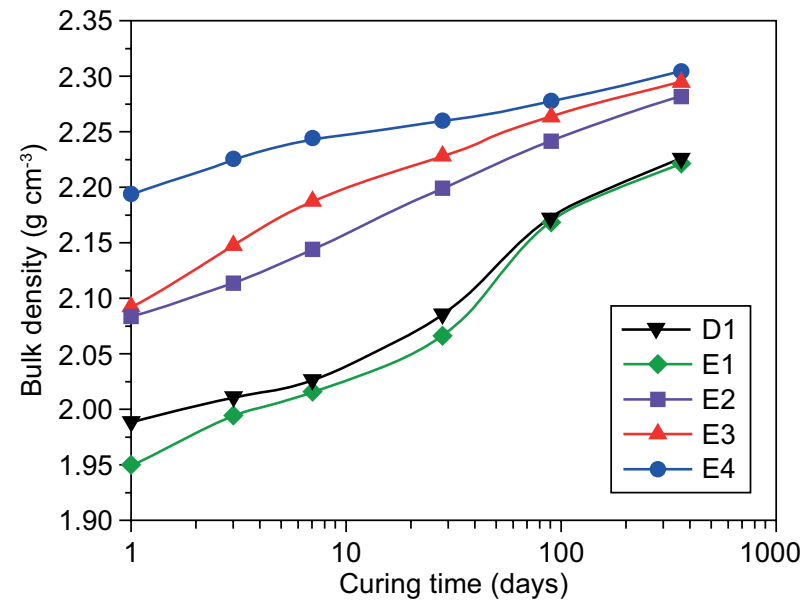

e)

Figure 6 . The bulk density of the pastes with and without the 4 mass \% SNP. 
higher $W_{n}$ values in comparison with the neat $\mathrm{OPC}$ and other cement pastes without the SNP. The SNP contain unsaturated bonds, and a high surface area make it extremely active. SNP act as active nucleation sites which accelerate the hydration reaction of the cement at early ages by the pozzolanic reaction with the $\mathrm{CH}$ releasing

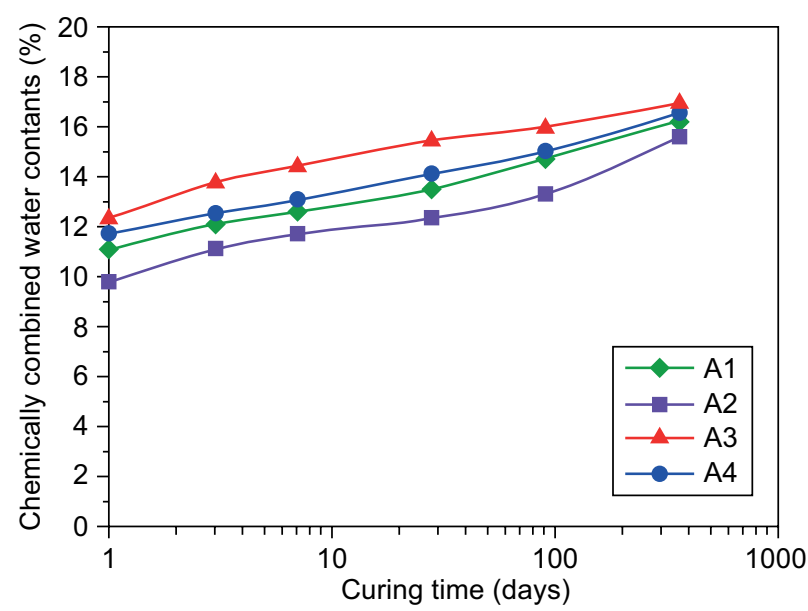

a)

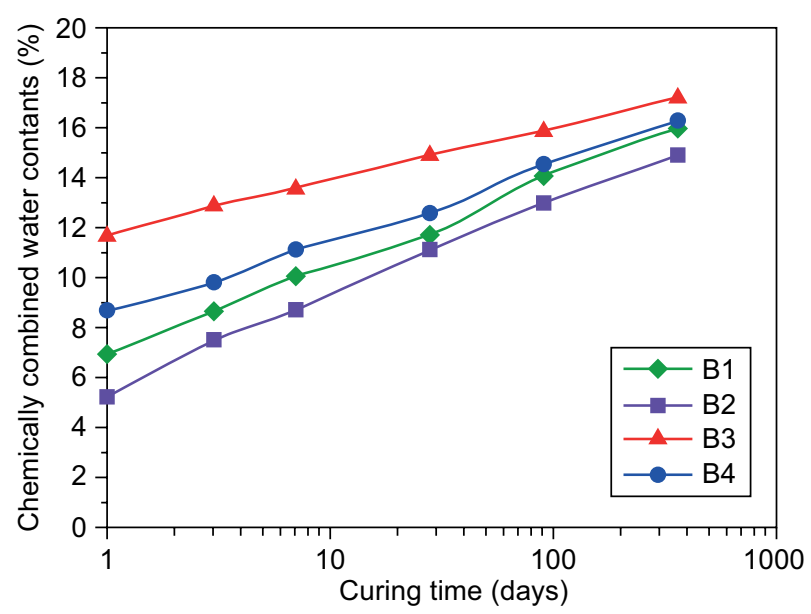

b)

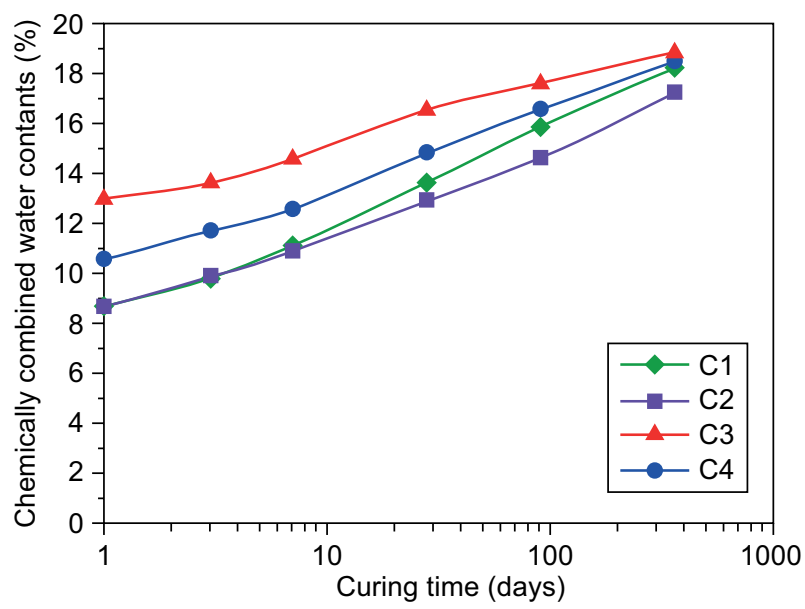

c) through the cement hydration to compose supplementary calcium silicate, calcium aluminate, and calcium aluminate products [53]. SNP enhance the production of the $\mathrm{CSH}$ structure to fill the voids between the cement grains to obtain a denser and stronger matrix [54, 55].

The data also show that the FA composite cement pastes have lower $W_{n}$ values, which matched the values to the OPC at 1,3 , and 7 days with $59 \%, 39 \%$, and $23 \%$, respectively, these value are lower than those values of the GS composite cement pastes by $25 \%, 13 \%, 5 \%$, $10 \%, 16 \%, 14 \%$, and $15 \%$ for $1,3,7,28,90$ and 360 days, respectively. The values of the $W_{n}$ decreases with a decrease in the GS as well as the OPC fraction as shown in the D and E mixes, where the D1 mix has higher $W_{n}$ values than the E1 mix especially at the early ages of hydration by $30 \%, 9 \%$, and $7 \%$ for specimens hydrated at 1, 3, 7 days, respectively.

\section{Free lime contents}

The free lime (FL) content of the composite cement pastes including the FA and or the GS with and without 4 mass \% SNP in the entity of the SP cured up to 360 days is demonstrated in Figure 8. The content of the FL in the

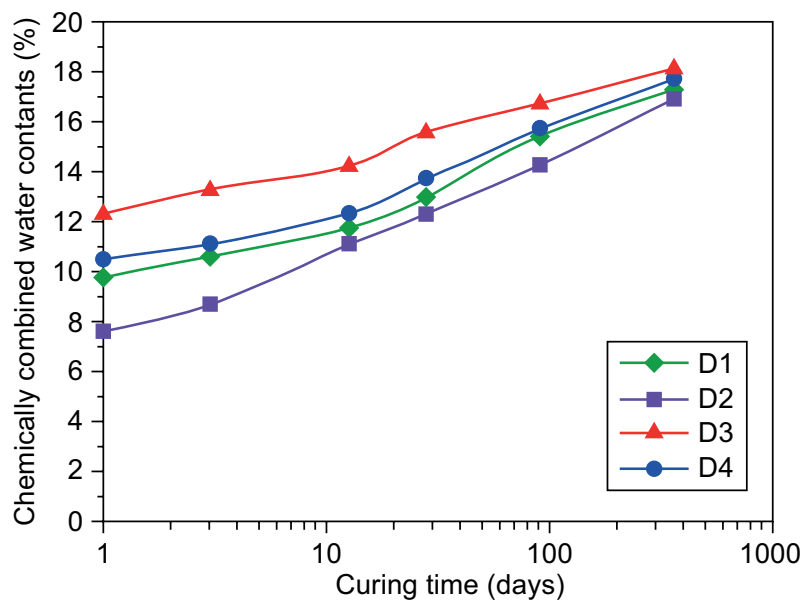

d)

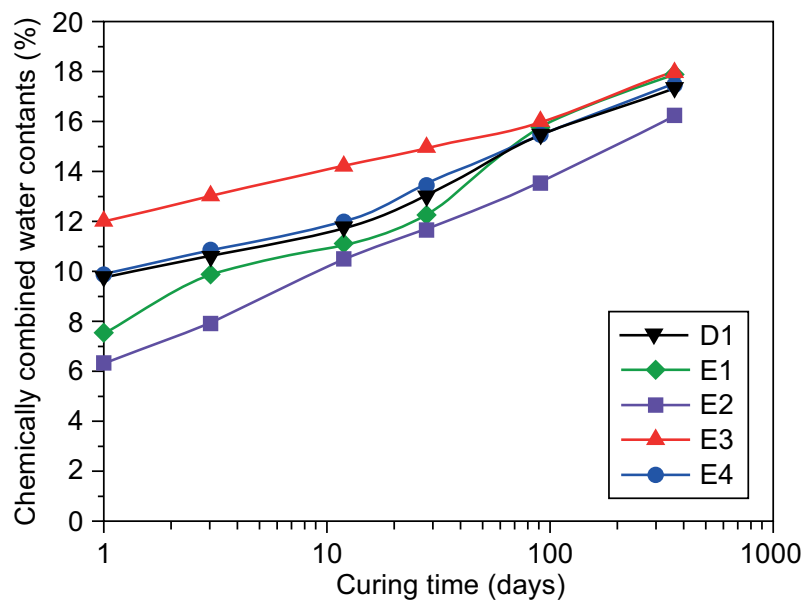

e)

Figure 7. The chemically combined water contents of the pastes containing the 4 mass $\%$ SNP. 
OPC cement pastes increases up to 360 days, attributed to the continued hydration reaction, liberating the $\mathrm{CH}$ through the hydration period as shown in Figure 8a. With the presence of 4 mass \% SNP, the FL content rises to 3 days then lowers up to 360 days. These processes are subjected to two different processes. The first process is

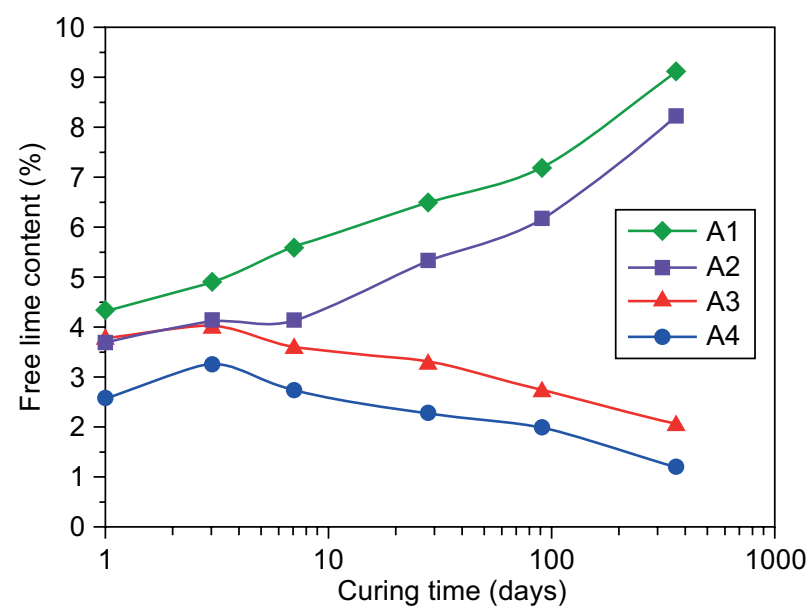

a)

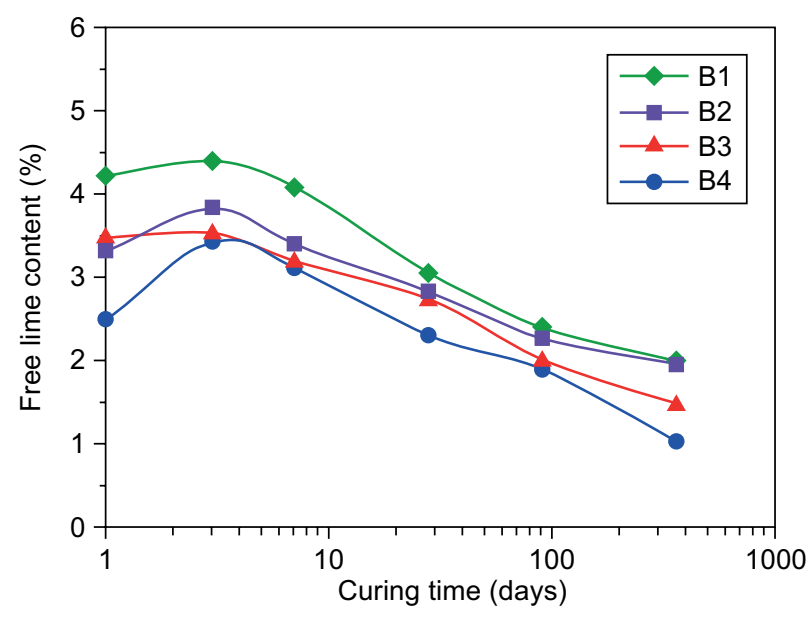

b)

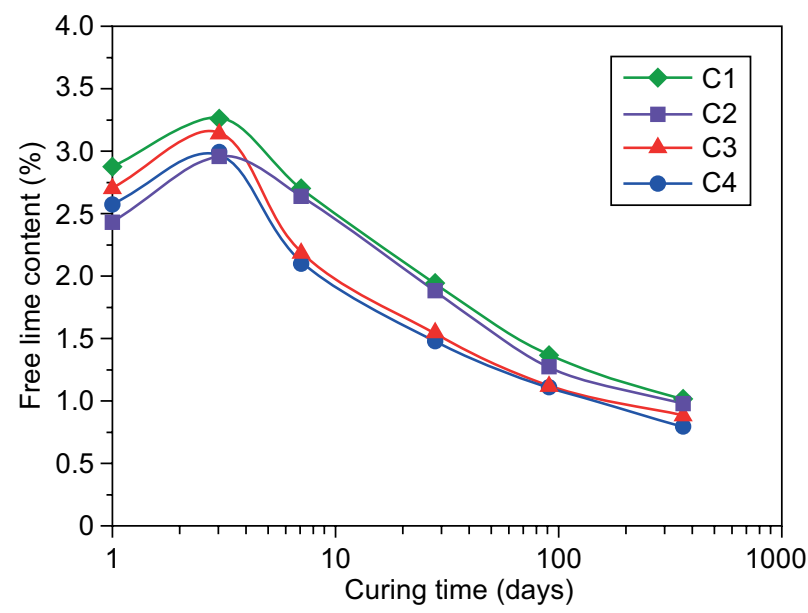

c) the FL increase (lime production); then the FL decreases in the second process (lime consuming). First, the SNP speed up the hydration of the cement phase reaction rate, mainly the releasing rate of the $\mathrm{CH}$ is faster than the consuming rate by the pozzolanic action with the SNP, in this step (the first process), the FL increases to 3 days [56]. In the second process, the FL of the composite cement pastes containing the FA, GS and/or SNP decreases (from 3 days up to 360 days) [57, 58]. Also, the SNP enhance the pozzolanic reaction in the hybrid with the GS, and the FA to react with the liberated $\mathrm{CH}$ (lime consumption), i.e., the FL decreases as shown in the mixes (Figures 8b-e). The E1 mixes have lower FL values than the values of the D1 mix by $8.3 \%, 18 \%$, $10 \%, 28 \%, 29 \%$, and $31 \%$ than the $\mathrm{C} 1 \mathrm{mix}$ by $41 \%$, $50 \%, 60 \%, 44 \%, 37 \%$, and $34 \%$ for the specimens hydrated at 1, 3, 7, 28, 90, and 360 days, respectively. The SNP in the collection of the SP help to progress the dispersal of the OPC and SNP; driving it to a highdegree of compaction and cementation and decreasing the porosity, which eases the narrowing gap between the SNP and the $\mathrm{CH}$ freed up forming further $\mathrm{CSH}$ with an increase in the $\mathrm{X}$ ratio.

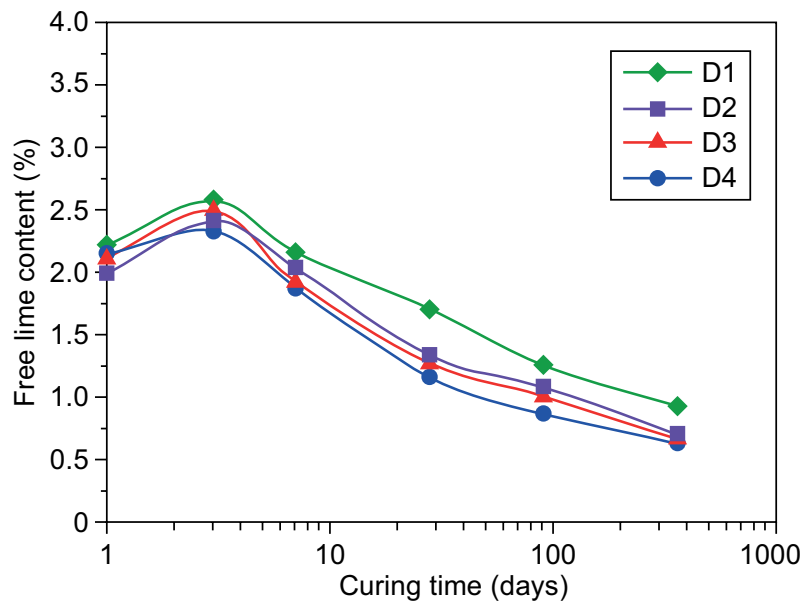

d)

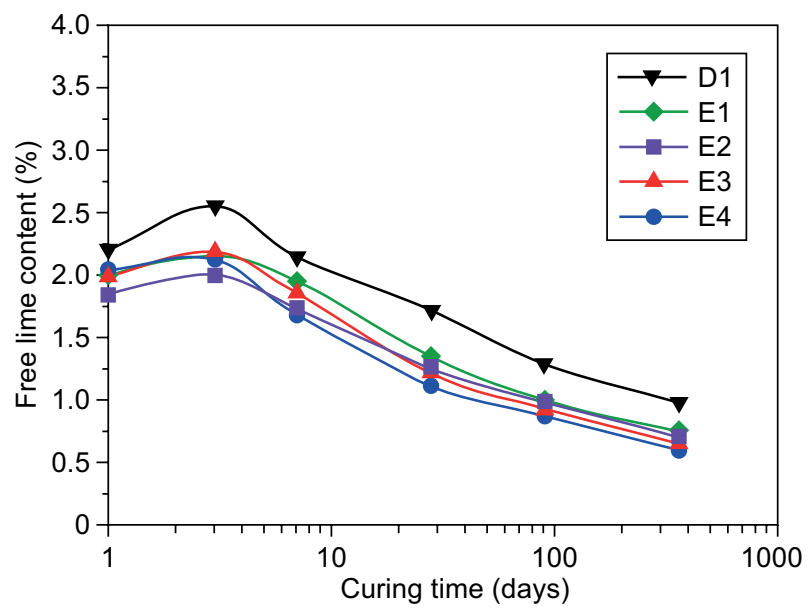

e)

Figure 8 . The free lime contents of the pastes with the 4 mass $\%$ SNP. 
Phase composition

\section{XRD patterns}

The XRD diffraction patterns of the selected hydrated mixes with and without the $4 \%$ SNP and $1 \%$ SP are shown in Figure 9. Figure 9 represents the hydrated and anhydrate phase diffraction lines corresponding to

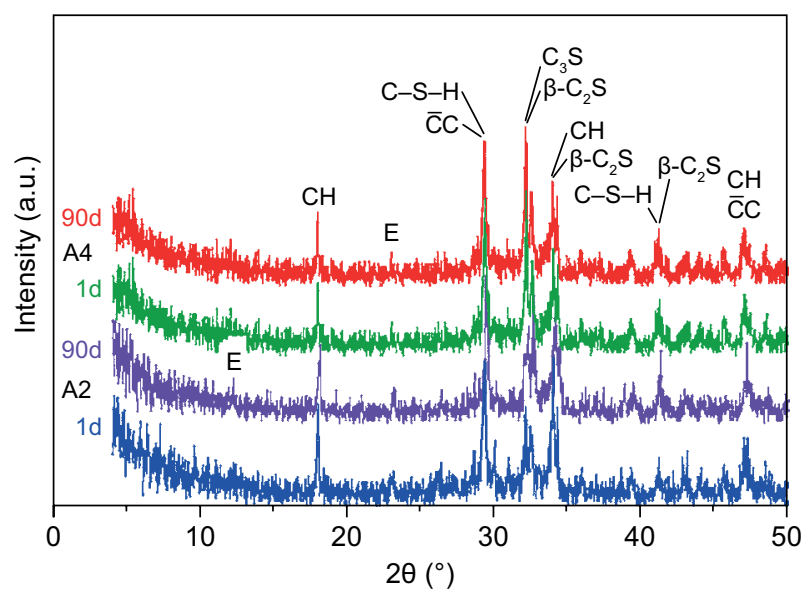

a)

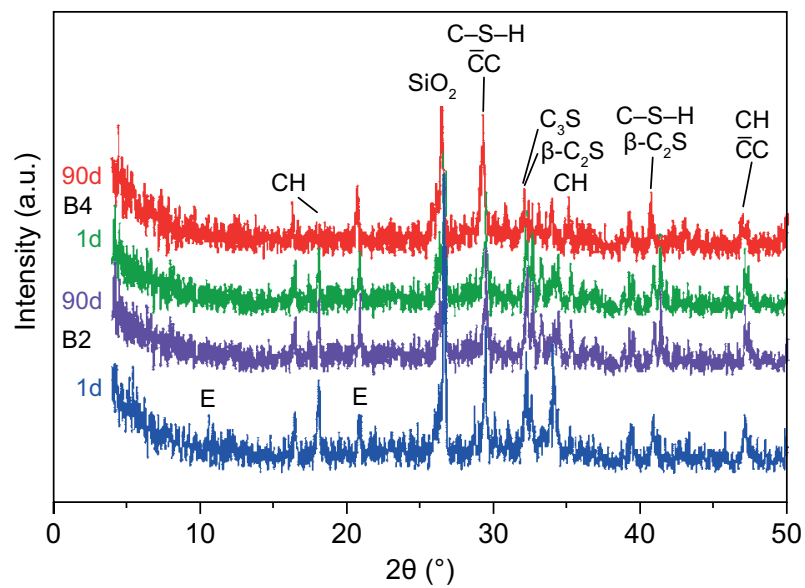

b)

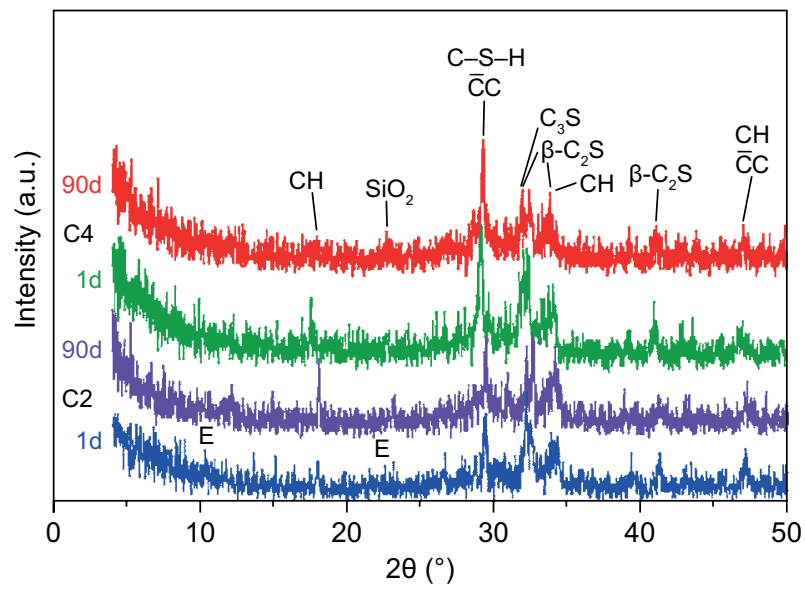

c)
$\mathrm{CH}, \beta-\mathrm{C}_{2} \mathrm{~S}, \mathrm{C}_{3} \mathrm{~S}, \mathrm{C} \overline{\mathrm{C}}, \mathrm{CSH}$, and ettringite. It is clear that the peaks of the $\mathrm{CH}$ show higher intensity in the OPC cement paste as shown in Figure 9a. As the hydration proceeds, the intensity of the peak characterising the $\mathrm{CSH}$ increases, this diffraction line is overlapped with that of the $C \bar{C}$ diffraction line, they increase with the hydration age; this is due to the hydration progress up to 360 days. The diffraction line characterising $\mathrm{CaCO}_{3}$ was detected at $3.03 \AA$, whereas the peaks corresponding to $\mathrm{CH}$ decrease from 1 day up to 90 days for the specimens containing the SNP (the A4, B4, C4, D4, E4 mixes). The diffraction lines corresponding to $\mathrm{CH}$ show a sharp decrease for the specimens containing $40 \% \mathrm{FA}, 40 \%$ GS, and or $20 \% \mathrm{FA}+20 \% \mathrm{GS}$, these lines nearly or completely disappear for the $\mathrm{C} 4$ and $\mathrm{E} 4$ mixes hydrated at 90 days. Besides, the quartz peaks were also detected as the main constituent of the cement pastes as shown in Figure $9 \mathrm{~b}$-e. Increasing the GS content, the intensities of the peaks characteristic of $\mathrm{CH}$ and $\mathrm{C} \overline{\mathrm{C}}$ decrease; as a result of lowering the percentage of the OPC, and the $\mathrm{CH}$ pozzolanic action with the SNP, FA, and GS as shown in Figure 9d-e.

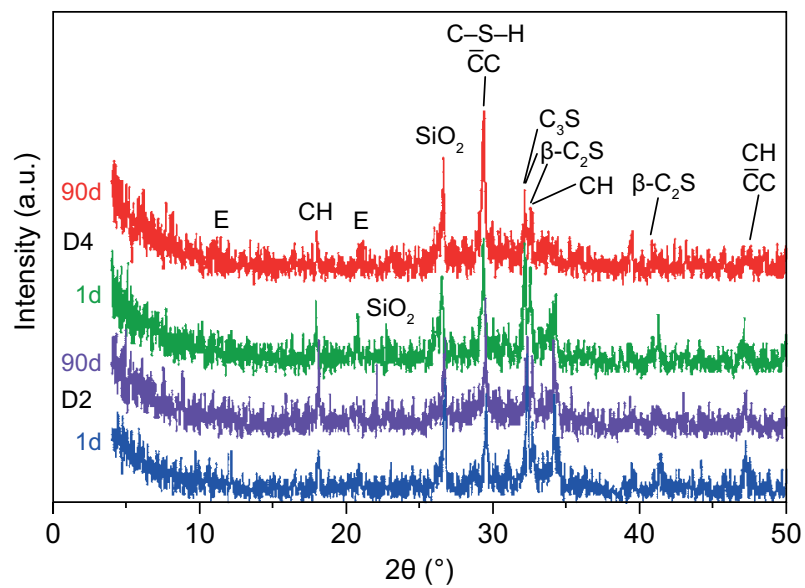

d)

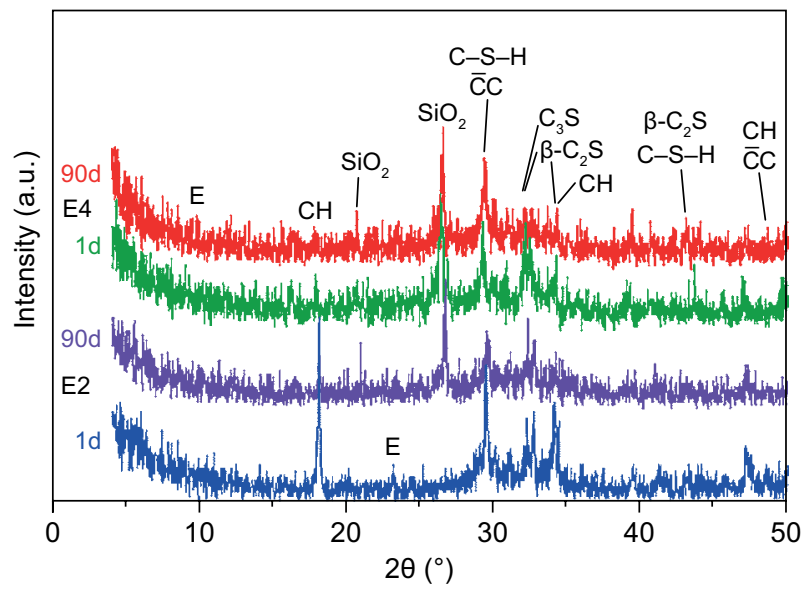

e)

Figure 9. The XRD patterns of the cement pastes with the 4 mass \% SNP cured at 1 day and 90 days. 
SNP have a higher impact on the composite cement hydration reaction and it manages as nano-sized SNP represented not only as filler, but also as an active component to increase the OPC phase hydration reaction. The pozzolanic activity of the SNP is higher than the FA and GS, therefore, the peak diffraction lines area of the CSH phase increase in the presence of the SNP.

\section{TGA/DTG thermograms}

The TGA/DTG thermograms of the hardened composite cement pastes in a hybrid of $4 \%$ SNP and $1 \%$ SP cured at one day and 90 days is shown in Figure 10.

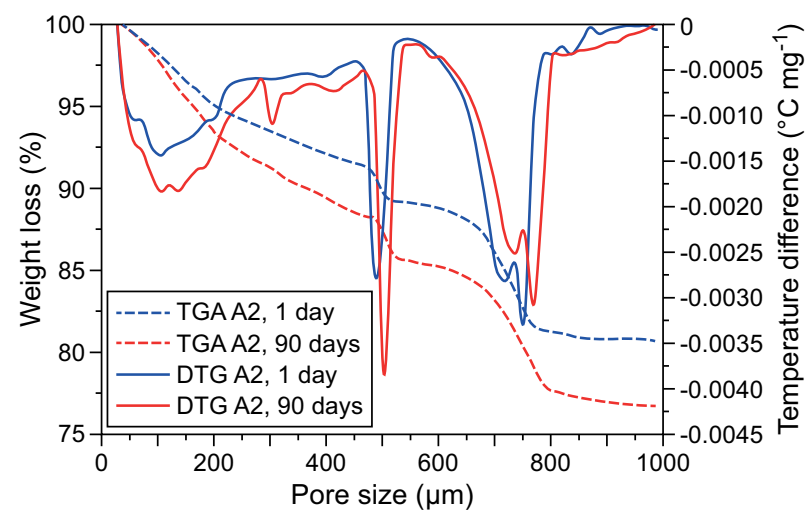

a)

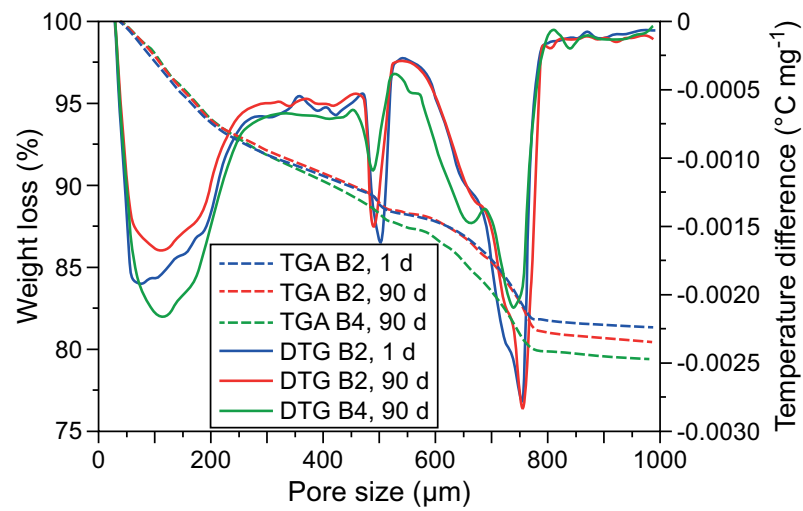

b)

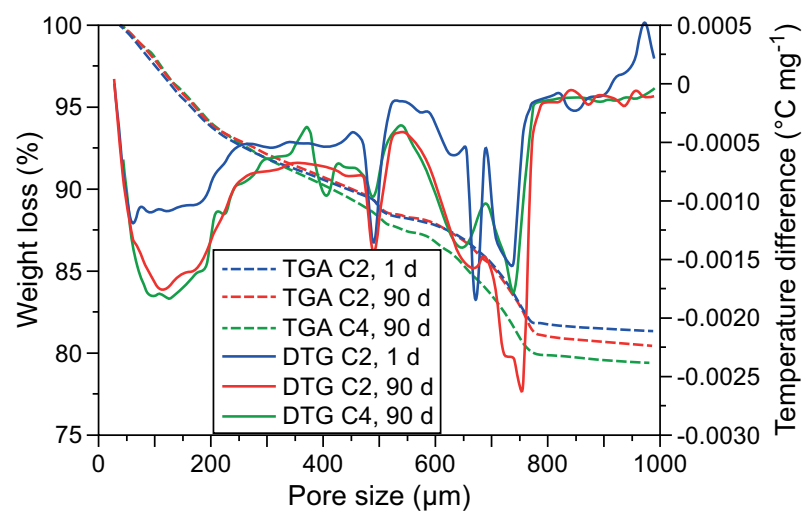

c)
The data obtained from the weight losses of the mixes hydrated for 1 day and 90 days at a temperature range $60-250{ }^{\circ} \mathrm{C}, 450-550{ }^{\circ} \mathrm{C}, 650-850{ }^{\circ} \mathrm{C}$, and $1000{ }^{\circ} \mathrm{C}$ are given in Table 3. Four endothermic peaks appear in the TGA/DTG thermograms at the $60-120,108-190$, $450-550$ and $650-850{ }^{\circ} \mathrm{C}$. The peaks at $60-120{ }^{\circ} \mathrm{C}$ are assigned to the decomposition of the calcium-silicate hydrate, tri-sulfoaluminate hydrate (AFt) and or the monosulfate-hydrated products (AFm). The peak located at

Table 3. The weight loss values of the OPC and composite cement pastes from the TGA-thermograms (\%).

\begin{tabular}{lccccc}
\hline Mix. & $\begin{array}{c}\text { Curing age } \\
\text { (days) }\end{array}$ & \multicolumn{4}{c}{ Temperature range $\left({ }^{\circ} \mathrm{C}\right)$} \\
\cline { 3 - 6 } & $\geq 250$ & $450-550$ & $650-850$ & 1000 \\
\hline $\mathrm{A} 2$ & 1 & 7.82 & 2.41 & 7.17 & 19.26 \\
$\mathrm{~A} 2$ & 90 & 8.81 & 2.96 & 7.25 & 21.26 \\
$\mathrm{~B} 2$ & 1 & 7.37 & 1.66 & 5.13 & 18.65 \\
$\mathrm{~B} 2$ & 90 & 7.80 & 1.70 & 5.89 & 19.55 \\
$\mathrm{~B} 4$ & 90 & 8.10 & 1.45 & 4.56 & 19.76 \\
$\mathrm{C} 2$ & 1 & 5.90 & 1.49 & 4.26 & 15.24 \\
$\mathrm{C} 2$ & 90 & 7.29 & 1.88 & 5.40 & 20.62 \\
$\mathrm{C} 4$ & 90 & 8.97 & 1.42 & 4.20 & 21.92 \\
$\mathrm{D} 2$ & 90 & 5.40 & 1.33 & 4.45 & 15.40 \\
$\mathrm{D} 4$ & 90 & 9.22 & 1.34 & 3.44 & 19.22 \\
$\mathrm{E} 2$ & 90 & 8.40 & 1.49 & 2.89 & 18.50 \\
$\mathrm{E} 4$ & 90 & 8.80 & 1.40 & 4.45 & 18.99 \\
\hline
\end{tabular}

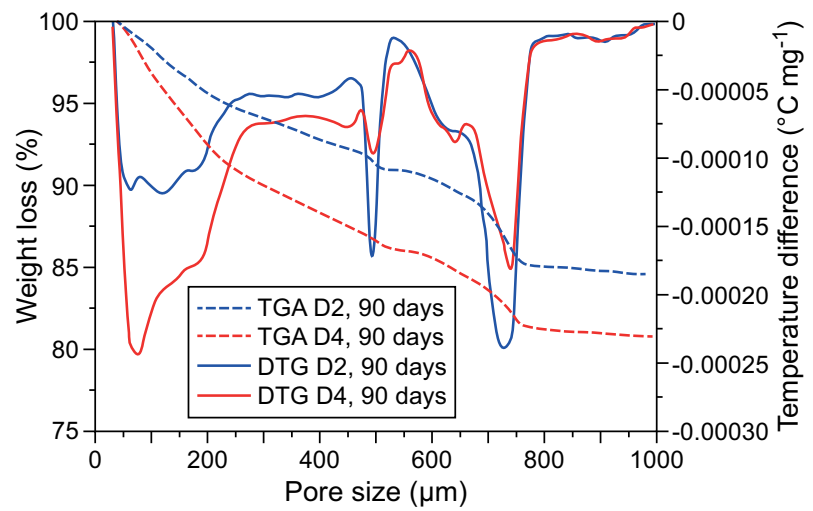

d)

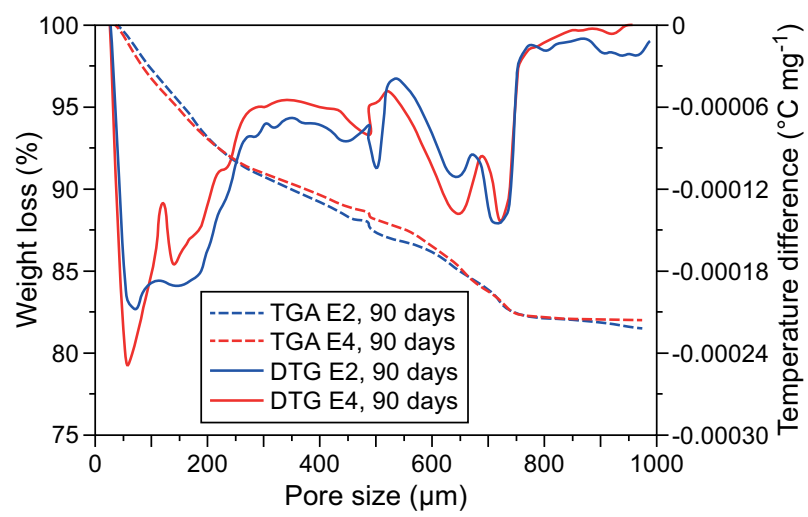

e)

Figure 10. The TGA/DTG thermograms of the cement pastes with the 4 mass \% SNP cured at 1 day and 90 days. 
$108-190{ }^{\circ} \mathrm{C}$ is related to the dehydration of the $\mathrm{CSH}$ in the different crystalline states, which overlapped with the calcium sulfoaluminate hydrates and calciumalumino-silicate-hydrates [59]. Whereas the peak of the endothermic direction at $450-550{ }^{\circ} \mathrm{C}$ corresponds to the dehydroxylation of $\mathrm{Ca}(\mathrm{OH})_{2}[60,61]$. The peak at $650-850{ }^{\circ} \mathrm{C}$ is attributed to the calcination of the amorphous and crystalline $\mathrm{C} \overline{\mathrm{C}}[62]$.

Figure 10a illustrates the TGA/DTG thermograms of A2 hydrated for 1 day and 90 days. The weight losses of the A2 mix hydrated for 1 day and 90a days at a temperature range of $60-250{ }^{\circ} \mathrm{C}, 450-550{ }^{\circ} \mathrm{C}$, $650-850{ }^{\circ} \mathrm{C}$ and $1000{ }^{\circ} \mathrm{C}$ was $7.82,2.41,7.17$, and $19.26 \%$ and $8.81,2.96,7.25$, and $21.26 \%$ for the A2 mix hydrated for the 1 day and 90 days, respectively. The peak areas corresponding to the $\mathrm{C}-\mathrm{S}-\mathrm{H}$ and $\mathrm{CH}$ phases increase with the curing time.

The effect of the partial replacement of the OPC by the FA, GS, and SNP can be calculated from the thermograms as shown in Figure 10b-c. The major countenance is the increase in the area of the $\mathrm{C}-\mathrm{S}-\mathrm{H}$ peak and decrease in the $\mathrm{CH}$ of the TGA/DTG-thermograms of the composite cement pastes containing the $4 \%$ SNP in comparison to the cement pastes without the SNP. The weight losses of B4 and C4 were $8.10,1.45,4.56$, and $19.46 \%$ and $8.97,1.72,4.20$, and $21.92 \%$ at the temperature-range of $60-250{ }^{\circ} \mathrm{C}, 450-550{ }^{\circ} \mathrm{C}, 650-850{ }^{\circ} \mathrm{C}$ and $1000^{\circ} \mathrm{C}$ hydrated at 90 days, respectively. Where the weight loss values of B2 and C2 were 7.80, 1.70, 5.89, and $19.55 \%$ and $7.29,1.88,5.4,20.62 \%$, respectively, as shown in Figure 10 and Table 3, this is due to the fact that the SNP accelerate the cement hydration reactions.

The results also show that increasing the GS content, the peak at $450-550{ }^{\circ} \mathrm{C}$, which is characteristic of the $\mathrm{CH}$ dihydroxylation, decreases as shown in Figures 10d-e. The two consecutive peaks at $650-850{ }^{\circ} \mathrm{C}$ are concerned with the decarbonisation of the amorphous and crystalline $\mathrm{C} \overline{\mathrm{C}}$ decreases as the GS content increases, where the weight losses of D2, E2, D4, and E4 cured at 90 days at a temperature range of $60-250{ }^{\circ} \mathrm{C}$ were found to be $5.40 \%, 8.40 \%, 8.80 \%$, and $9.22 \%$, respectively. The major countenance is the increase in the peak area of the CSH of the E2 and E4 mixes more than the D2 and D4 mixes.

\section{Microstructure and morphology of the composite cement pastes}

The microstructure and morphology of the hardened OPC composite cement pastes is shown in Figures 11 and 12. Figure 11a-f displays the microstructure of the OPC and composite cement pastes containing $40 \%$ FA, $40 \% \mathrm{GS}$, and or $4 \% \mathrm{SNP}$, the A2, B2, B4, and C4 mixes hydrated for 1 and 90 days. The micrograph displays the existence of crystalline calcium silicate hydrate and layers of hexagonal $\mathrm{CH}$ crystals with a flocculent and porous structure as shown in Figure 11a. Figure 11b depicts a large amount of calcium silicate hydrate gel accountable for interlocking a rigid and closed cementitious system with an increase in the curing age up to 90 days.

Figure 11c-d displays the SEM photo of the B2 specimen treated at 1 day and 90 days. This photo depicts a surface-layer film of crystalline $\mathrm{C}-\mathrm{S}-\mathrm{H}$ hydrated products that was formed around the FA and or OPC pastes after 1 day (Figure 11c). After 90 days, the hydrated products mainly formed non-compact and fibrous $\mathrm{C}-\mathrm{S}-\mathrm{H}$ crystalline and $\mathrm{CH}$ crystals embedded in the pores of the hydrated products. The FA particles that are partially and or fully-hydrated show a dense rim in the inner hydrated product, however, the morphology of the composite pastes shows a wide-ranging microstructure having a great number of pores as shown in Figure 11d [63].

Figure 11e-f represents the micrographs of the FA-GS-SNP composite cement pastes with 4 mass \% SNP and the B4 and C4 mixes cured at 90 days to represent the synergetic effect of the SNP on the modification of the microstructure and physicochemical and mechanical characteristics of the composite cements. The SEM micrograph of the hardened B4 mix hydrated at 90 days shows the existence of a prolonged $\mathrm{CSH}$ as a rod-like particle of having a denser structure, which is mainly composed of fully nano-crystalline hydrated products (Figure 11e). The micrograph of $\mathrm{C} 4$ displayed the formation of a compact morphology with a marked reduction in the porosity of the hardened cement paste made of OPC-GS-SNP, which produces the higher CS values (Figure 11f).

Figures 12a-d shows the micrograph of the composite cement pastes, the eD2, D4, E2, and E4 mixes cured up to 90 days. The SEM micrograph of the D2 mix depicts the wide microstructure, a great number of pores available for the formation of more hydrates (Figure 12a). On the one hand, the presence of SNP within the D4 mix fills some of the pores and decreases the $\mathrm{CH}$ crystals then increases the growth of the $\mathrm{CS}$, but the microstructure of binder is a closed structure with micro- or nano-pores [64]. The useful effect of the OPC-FA-GS-SNP composite cement pastes result from the modified microstructure of the cementitious pastes (Figure 12b). The micrograph of the E2 mix hydrated at 90 days depicts the presence of a fibrous $\mathrm{CSH}$ and it contains a lesser compact structure. In the presence of 40 mass \% GS in the hybrid of 4 the mass \% SNP can reduce the pore size. The SNP act as a centre to promote the cement hydration. The micrograph displayed the formation of a dense compact structure and the $\mathrm{CH}$ crystal cannot be found in the matrix and with a marked reduction in the porosity of the hardened cement paste made of $36 \%$ OPC $+40 \%$ FA $+40 \%$ GS $+4 \%$ SNP, the $\mathrm{E} 4 \mathrm{mix}$ (Figure 12e). 


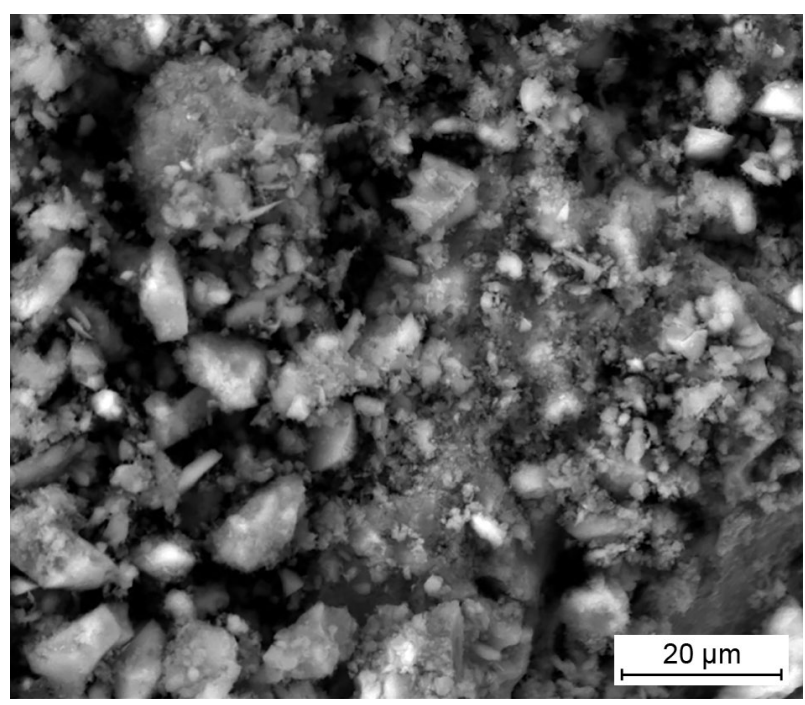

a) A2 - 1 day

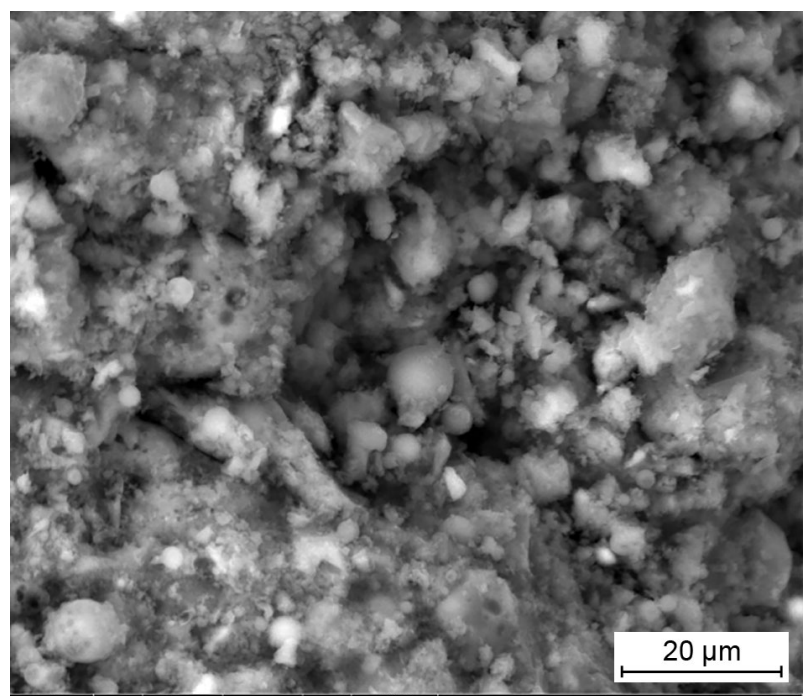

c) B2 - 1 day

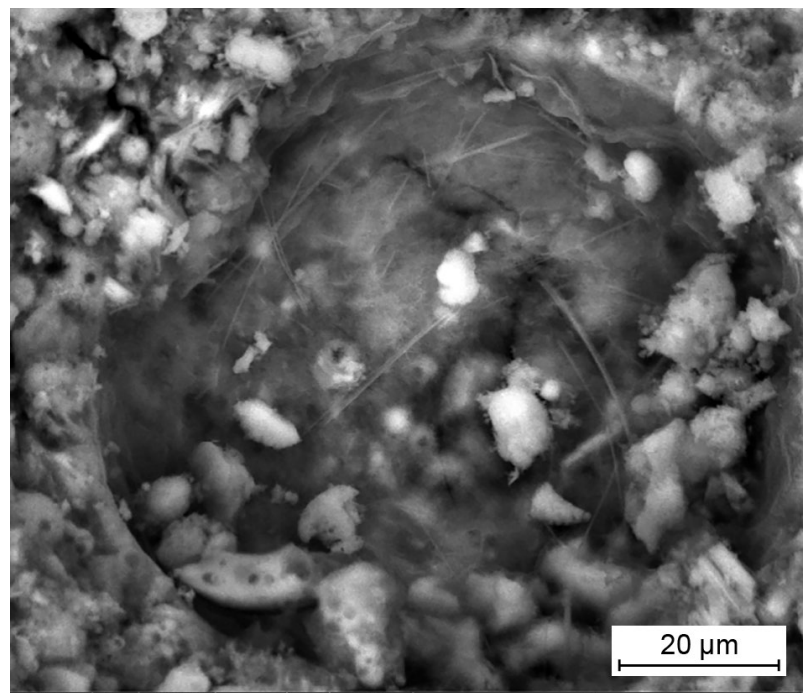

e) B4 - 90 days

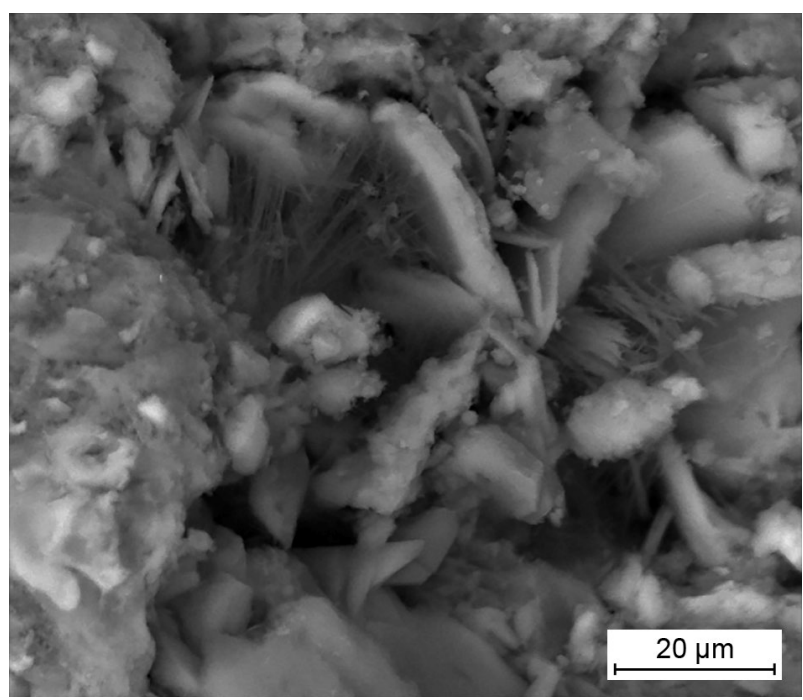

b) A2 - 90 days

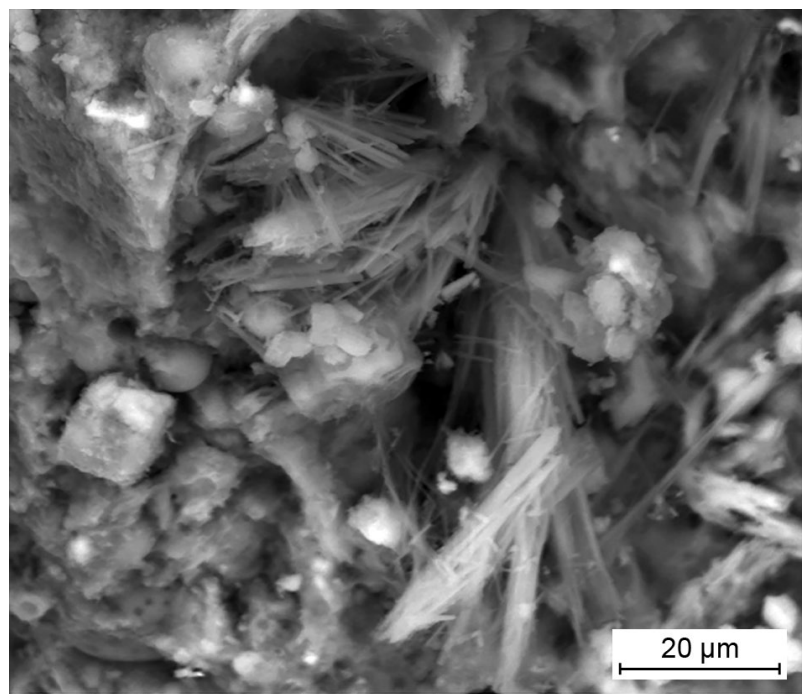

d) B2 - 90 days

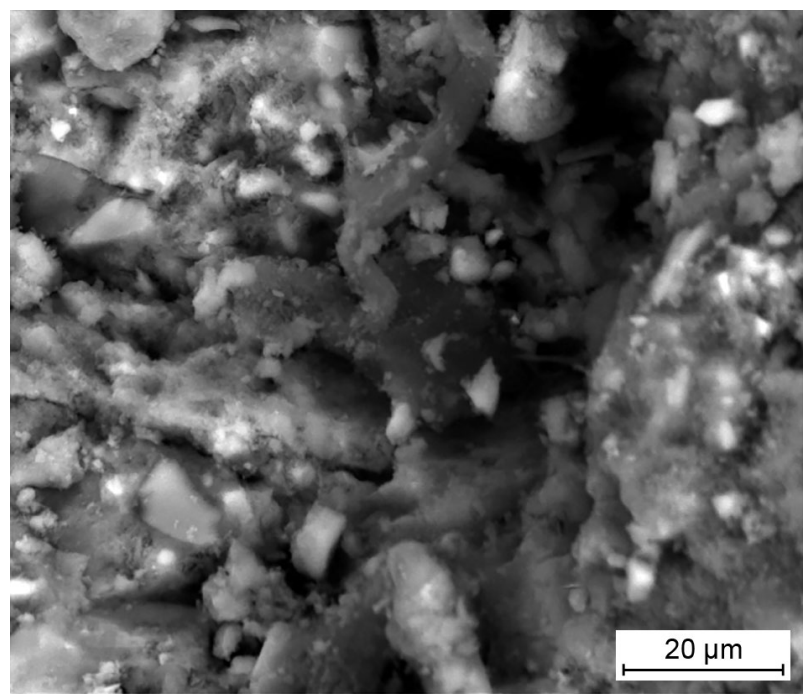

f) C4 - 90 days

Figure 11. The SEM micrograph of the composite cement pastes; a) A2 - 1 day; b) A2 - 90 days; c) B2 - 1 day; d) B2 - 90 days; e) B4 - 90 days; f) C4 - 90 days. 


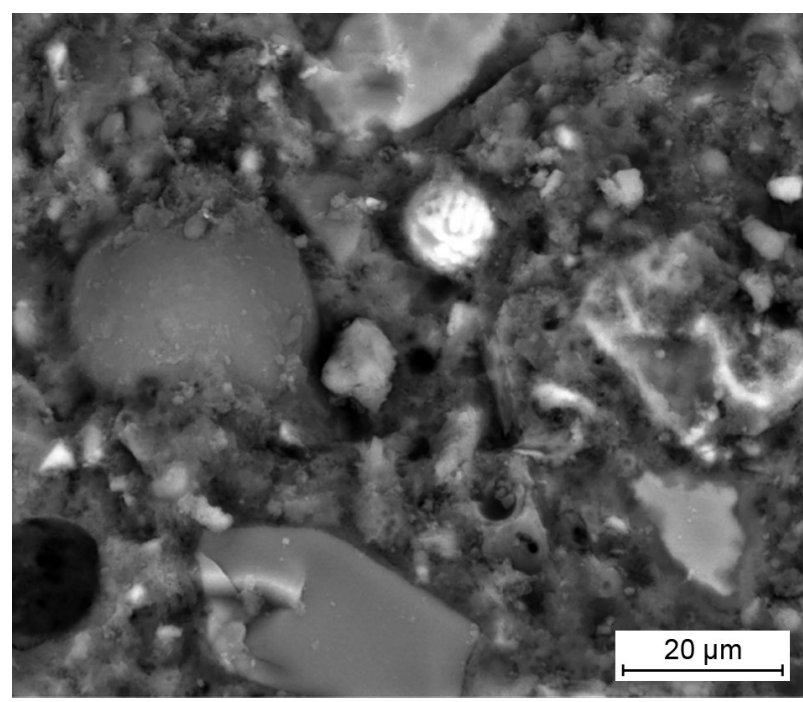

a) D2 - 90 days

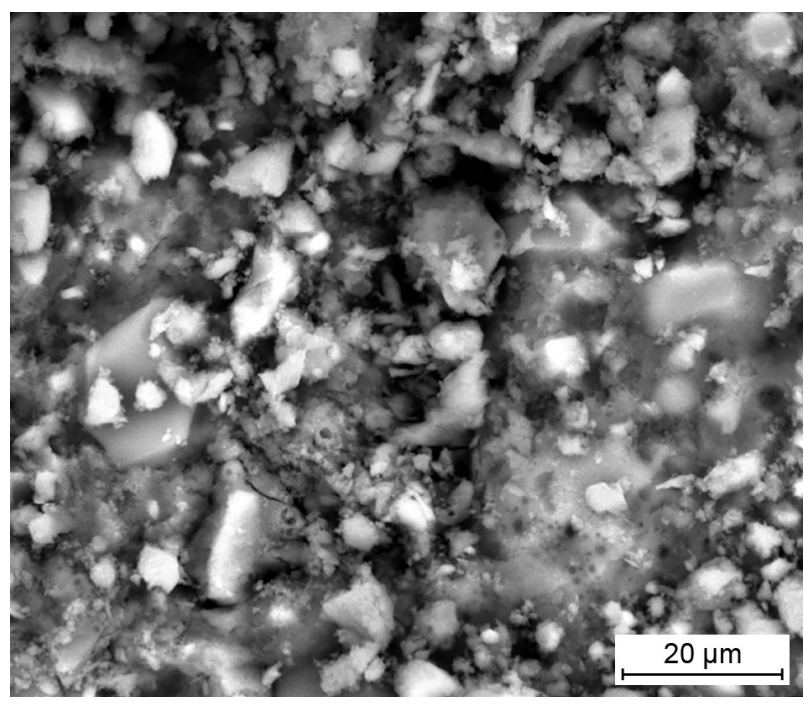

c) E2 - 90 days

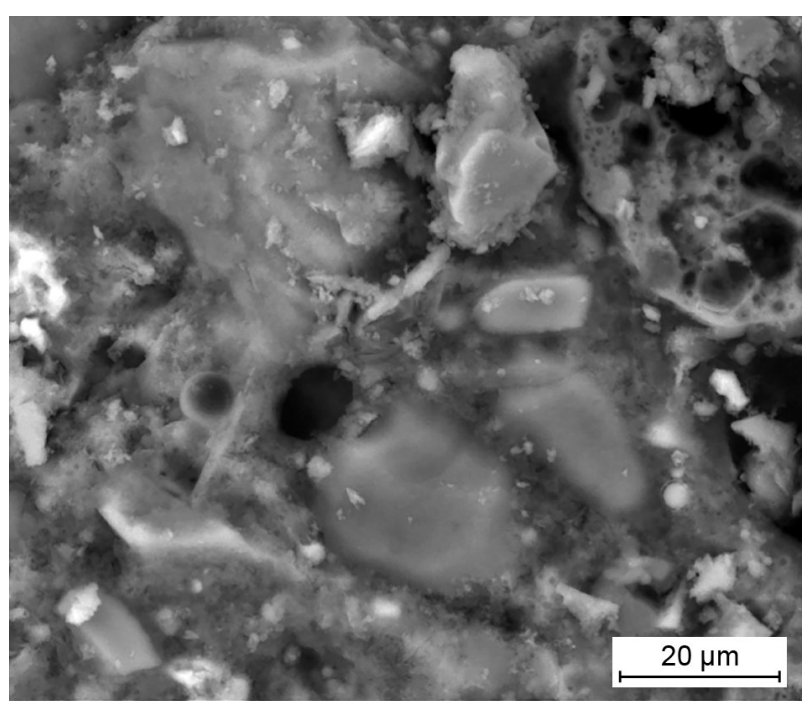

b) D4 - 90 days

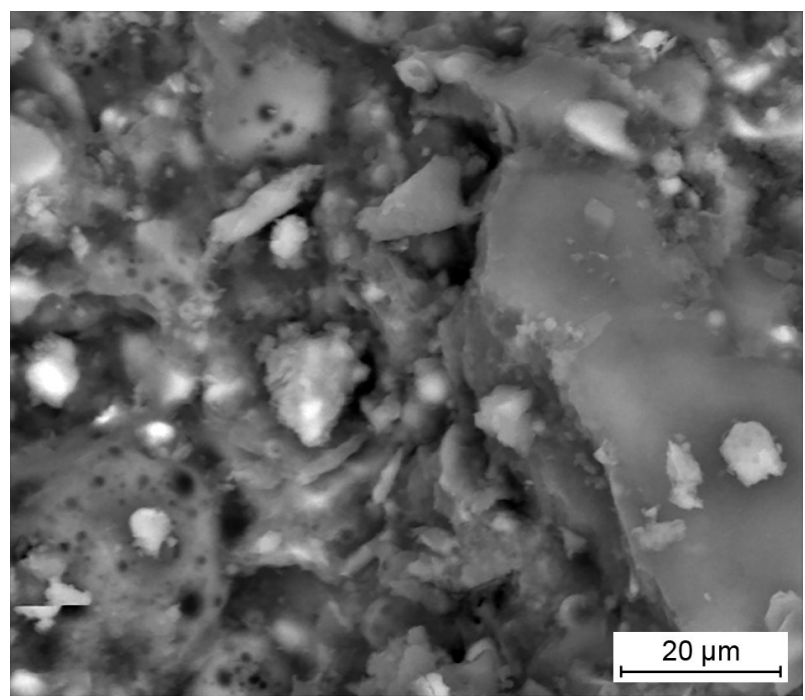

d) E4 - 90 days

Figure 12. The SEM micrograph of the composite cement pastes; a) D2 - 90 days; b) D4 - 90 days; c) E2 - 90 days; d) E4 - 90 days.

\section{CONCLUSIONS}

It can be concluded that:

- SNP act like a strenuous centre promoting cement hydration, which conduct itself as both an active ingredient and a nano-filler enhancing hydration reaction of the OPC and perfect pozzolanic nano-material in comparison with the FA and GS.

- The composite cement pastes with $4 \%$ SNP seek a higher $\mathrm{W} / \mathrm{C}$ ratio and shorter STs compared to other composite cement pastes without the SNP.

- The values of the CS of the cement having the GS are greater than the OPC and the composite cements containing the FA pastes.

- The results show an increase in the $X$ ratio of the composite cementitious binders in the hybrid of $4 \%$ SNP and $1 \%$ SP.
- The values of the TP in the composite cementitious binders in the hybrid of $4 \%$ SNP and $1 \%$ SP are lower than that those of the OPC pastes.

- The results of the physicomechanical properties, namely the CS, $X$ ratio, TP, and BD are in a good agreement with each other. On the other hand, the increase in the replacement OPC with 20 mass \% FA + 40 mass \% GS +4 mass \% SNP, the E4 mix show a higher $\mathrm{CS}$ value with results of the A4 mix, although the OPC was replaced by 20 mass $\%$ FA +40 mass $\%$ $\mathrm{GS}+4$ mass \% SNP.

- It was recommended that the composite cements containing 36 mass $\%$ OPC +40 mass $\% \mathrm{FA}+40$ mass $\%$ $\mathrm{GS}+4$ mass \% SNP, the E4 mix, is the suitable optimum mix composition, which showed a dense compact structure mainly composed of nano-crystalline hydrated products and the $\mathrm{CH}$ crystal cannot be found in the cement matrix with a marked decrease in the TP of the hardened cements with a higher CS. 


\section{REFERENCES}

1. Imbabi M.S, Carrigan C., Mekenna S. (2013): Trends and developments in green cement and concrete technology. International Journal of Sustainable Built Environment, 1, 194-216. doi: 10.1016/j.ijsbe.2013.05.001

2. Juenger M.C.G., Winnefeld F., Provis J.L., Ideker J. (2011): Advances in alternative cementitious binders. Cement Concrete Research, 41, 1232-1243. doi: 10.1016/j. cemconres.2010.11.012

3. Li H., Xiao H., Yuan J., Ou J. (2004): Microstructure of cement mortar with nano-particles. Composites: Part B, 35, 185-189. doi: 10.1016/S1359-8368(03)00052-0

4. Jo B. W., Kim C. H, Tae G. H, Park J. B. (2007): Characteristics of cement mortar with nano- $\mathrm{SiO}_{2}$ particles. Construction and Building Material, 21, 1351-1355. doi: 10.1016/j.conbuildmat.2005.12.020

5. Ababneh F.A., Alakhras A.I., Heikal M., Ibrahim S.M.. (2019): Stabilization of lead bearing sludge by utilization in fly ash-slag based geopolymer, Construction and Building Materials, 227, 116694. doi: 10.1016/j.conbuildmat.2019. 116694

6. Li G. (2004): Properties of high-volume fly ash concrete incorporating nano- $\mathrm{SiO}_{2}$. Cement and Concrete Research, 34(6), 1043-1049. doi: 10.1016/j.cemconres.2003.11.013

7. QingY., Zenan Z., Li S., Rongshen, C. (2008): A comparative study on the pozzolanic activity between nano- $\mathrm{SiO}_{2}$ and silica fume. Journal of Wuhan University of Technology - Materials Science Edition, 21, 153-157. doi: 10.1007/ BF02840907

8. Sanchez F., Sobolev K. (2010): Nanotechnology in concrete - a review, Construction and Building Materials, 24, 2060-2071. doi: 10.1016/j.conbuildmat.2010.03.014

9. Lee B.Y., Kurtis K.E.(2010): Influence of $\mathrm{TiO}_{2}$ Nanoparticles on Early $\mathrm{C}_{3} \mathrm{~S}$ Hydration. Journal of the American Ceramic Society, 93(10), 3399-3405. doi: 10.1111/j.15512916.2010.03868.x

10. Metaxa Z.S., Konsta-Gdoutos M.S, Shah S.P. (2009): Carbon nano-tubes Reinforced Concrete, Nanotechnology of Concrete. ACI special publication, 267, 11-20. doi: 10. 3141/2142-17

11. Oltulu M., Sahin R. (2011): Single and combined effects of nano- $\mathrm{SiO}_{2}$, nano- $\mathrm{Al}_{2} \mathrm{O}_{3}$ and nano- $\mathrm{Fe}_{2} \mathrm{O}_{3}$ powders on compressive strength and capillary permeability of cement mortar containing silica fume. Materials Science and Engineering A, 528, 7012-7019. doi: 10.1016/j.msea.2011. 05.054

12. Ge Z., Gao Z. Applications of Nanotechnology and Nanomaterials in Construction. In: First Internat. Conf. on Constr. In Develop. Countries (ICCIDC-I): "Advancing and Integrating Construction Education, Research \& Practice", Karachi, Pakistan, pp.235-240. doi: 10.1007/978-981-106214-8_6

13. Hanehara S., Ichikawa M. (2001): Nanotechnology of cement and concrete. Journal of the Taiheiyo Cement Corporation, 141, 47-58. doi: 10. 1016/j.acme.05.010

14. Scrivener K.L. (2009). Nanotechnology and cementitious materials. in: Scrivener K.L., Bittnar Z., Bartos P.J.M., Nemecek J., Smilauer V., Zeman J. (Eds.) Nanotechnology in Construction: Proceedings of the NICOM $3 ; 3^{\text {rd }}$ International Symposium on Nanotechnology in Construction. Czech Republic, pp. 37-42. doi:10.1007/978-3-642-00980-8_4
15. Sobolev K., Shah S.P. (2008). Nanotechnology of Concrete: Recent Developments and Future Perspectives. American Concrete Institute, Detroit, 236, SP-254. doi: 10.1007/9783-642-00980-8 9 .

16. Heikal M., Ali A.I., Ismail M.N., Awad S., Ibrahim N.S. (2014): Behavior of composite cement pastes containing silica nano-particles at elevated temperature. Construction and Building Materials, 70, 339-350. doi: 10.1016/j. conbuildmat.2014.07.078

17. Heikal M., Al-Duaij O.K., Ibrahim N.S. (2015): Microstructure of composite cements containing blast-furnace slag and silica nano-particles subjected to elevated thermally treatment temperature. Construction and Building Materials, 93,1067-1077. doi: 10.1016/j.conbuildmat.2015. 05.042

18. Sobolev K., Ferrada M. (2005): How nanotechnology can change the concrete World. American Ceramic Society Bulletin, 10, 14-17. doi: 10.1002/9780470588260.ch16

19. Li G. (2004): Properties of high-volume fly ash concrete incorporating nano- $\mathrm{SiO}_{2}$. Cement and Concrete Research, 34, 1043-1049. doi: 10.1016/j.cemconres.2003.11.013

20. Nazari A., Riahi S. (2011): The effects of $\mathrm{SiO}_{2}$ nanoparticles on physical and mechanical properties of high strength compacting concrete. Composites Part B: Engineering, 42, 570-578. doi: 10.1016/j.compositesb.2010.09.025

21. Qing Y., Zenan Z., Li S., Rongshen C. A. (2008): Comparative study on the pozzolanic activity between nano$\mathrm{SiO}_{2}$ and silica fume. Journal of Wuhan University of Technology - Materials Science. Edition, 21, 153-157. doi: 10.1007/BF02840907

22. Jennings H.M., Bullard J.W., Thomas J.J., Andrade J.E., Chen J.J., Scherer G.W. (2008): Characterization and modeling of pores and surfaces in cement paste: correlations to processing and properties. Journal of Advanced Concrete Technology, 6, 5-29. doi: 10.3151/jact. 2008.6.5

23. Min-Hong Z., Jahidul I., Sulapha P. (2012): Use of nanosilica to increase early strength and reduce setting time of concretes with high volumes of slag. Cement and Concrete Composite, 34, 650-662. doi: 10.1016/j.conbuildmat.2011. 11.013

24. Abd El Aleem S., Heikal M., Morsi W.M. (2014): Hydration characteristic, thermal expansion and microstructure of cement containing nano-silica. Construction and Building Material, 59, 151-60. doi: 10.1016/j.conbuildmat.2014. 02.039

25. Naji Givi A., Abdul Rashid S., Nora A., Aziz F., Amran Mohd Salleh, M. (2011): The effects of lime solution on the properties of $\mathrm{SiO}_{2}$ nano-particles binary blended concrete. Composites Part B, 42, 562-569. doi: 10.1177/0021998310378908

26. Said A.M., Zeidan M.S., Bassuoni M.T., Tian Y. (2012): Properties of concrete incorporating nano-silica. Construction and Building Material, 36, 838-844. doi: 10.1016/j. conbuildmat.2012.06.044

27. Tao J. (2005): Preliminary study on the water permeability and microstructure of concrete incorporating nano$\mathrm{SiO}_{2}$. Cement and Concrete Research, 35, 1943-1947. doi: 10.1016/j.cemconres.2005.07.004

28. Hou P., Cheng X., Qian J., Zhang R., Cao W., Shah S.P. (2015): Characteristics of surface treatment of nano- $\mathrm{SiO}_{2}$ on the transport properties of hardened cement pastes with different water-to-cement ratios. Cement and Concrete Composite, 55, 26-33. doi: 10.1016/j.cemconcomp.2014. 07.022 
29. Qing Y., Zenan Z., Deyu K., Rongshen K. (2007): Influence of nano- $\mathrm{SiO}_{2}$ addition on properties of hardened cement paste as compared with silica fume. Construction Building Material, 21, 539-545. doi: 10.1016/j.conbuildmat.2005. 09.001

30. Lin K.L., Chang W.C., Lin D.F., Luon H.L., Tsai M.C. (2008): Effects of nano- $\mathrm{SiO}_{2}$ and different ash particle sizes on sludge ash-cement mortar. Journal of environmental management, 88, 708-714. doi: 10.1016/j.jenvman.2007. 03.036

31. Li H., Xiao H., Yuan J., Ou J. (2004): Microstructure of cement mortar with nanoparticles. Composites Part B: Engineering, 35, 185-189. doi: 10.1016/S1359-8368(03) 00052-0

32. Ghasemi A.M.R., Parhizkar T., Ramezanianpour A.A. (2010): Influence of colloidal nano- $\mathrm{SiO}_{2}$ addition as silica fume replacement material in properties of concrete. In: Proceeding of the second international conference on sustainable construction materials and technologies. Ancona, Italy.

33. Wang X. (2017): Effects of nanoparticles on the properties of cement-based materials. Construction and Environmental Engineering, 1-180. Doi: 10.31274/etd-180810-5865

34. Wang L., Zheng D., Zhang S., Cui H., Li D. (2016): Effect of Nano- $\mathrm{SiO}_{2}$ on the Hydration and Microstructure of Portland Cement. Nanomaterials, 6, 241. doi: 10.3390/ nano6120241

35. El-Didamony H., Abd El-Aleem' S., Abd El-Rahman R. (2016): Hydration Behavior of Composite Cement Containing Fly Ash and Nano-sized-SiO ${ }_{2}$. American Journal of Nano Research and Applications, 4, 6-16. doi: 10.11648/j.nano.20160402.11

36. Roychand R., Silva D., Setunge S. (2018): Nanosilica Modified High-Volume Fly Ash and Slag Cement Composite: Environmentally Friendly Alternative to OPC. Journal of Materials in Civil Engineering, 30. doi: 10.1061/ (ASCE)MT.1943-5533.0002220

37. Ehsani A., Nili M., Shaabani K. (2017): Effect of Nanosilica on the Compressive Strength Development and Water Absorption Properties of Cement Paste and Concrete Containing Fly Ash. Journal of Civil Engineering, 21, (2017), 1854-1865. doi: 10.1007/s12205-016-0853-2

38. Gao X., Yu Q.L., Brouwers H.J.H. (2015): Characterization of alkali activated slag-fly ash blends containing nanosilica. Construction and Building Materials, 98, 397-406. doi: 10.1016/j.conbuildmat.2015.08.086

39. Biricik H., Sarier N. (2013): Comparative Study of the Characteristics of Nano Silica-, Silica Fume- and Fly AshIncorporated Cement Mortars. Materials Research, 17, 570-582. doi: 10.1590/S1516-14392014005000054

40. ASTM Designation, C191. (2008): Standard method for normal consistency and setting of hydraulic cement, ASTM Annual Book of ASTM Standards. doi: 10.1520/C0191-08

41. Abd-El Aziz M.A., Heikal M., Abd El Aleem S. (2012): Physico-chemical and mechanical characteristics of pozzolanic cement pastes and mortars hydrated at different curing temperatures. Construction and Building Material, 26, 310-316. doi: 10.1016/j.conbuildmat.2011.06.026

42. El-Didamony H., Abd-El Eziz M., Abd El Aleem S., Heikal M. (2005): Hydration and durability of sulfate resisting and slag cement blends in Qaron's Lake water. Cement and Concrete Research, 35, 1592-1600. doi: 10.1016/j. cemconres.2004.06.038
43. Abd-El-Eziz M.A., Heikal M. (2009): Hydration characteristics and durability of cements containing fly ash and limestone subjected to Qaron's Lake Water. Advanced Cement Research, 21, 91-9. doi: 10.1680/adcr.2007.00025

44. ASTM C109, (2007). Strength test method for compressive strength of hydraulic cement mortars.

45. Collepardi M. (2006). The new concrete. Grafiche Tintoretto.

46. EL-Didamony H., Heikal M., Al-Masry S. (2012): Effect of delaying addition time of superplacticizier on hydration characteristics of blended cement pastes. Ceramics Silikaty, 56(3), 245-253

47. Heikal M., Abd.El.Aleem S., Morsi W.M. (2013): Characteristics of blended cements containing nano-silica. $H B R C$ Journal, 9, 243-255. doi: 10.1016/j.hbrcj.2013.09.001

48. Taylor H.F.W. (1997). Cement Chemistry. $2^{\text {nd }}$ ed., London, Thomas Telford Publishing.

49. Khatib J.M., Hibbert J.J. (2005): Selected engineering properties of concrete incorporating slag and metakaoline. Construction and Building Material, 19, 460-472. doi: 10.1016/j.conbuildmat.2004.07.017

50. Deschner F., Winnefeld F., Lothenbach B., Seufert S., Schwesig P., Dittrich S., Goetz-Neunhoeffer F., Neubauer J. (2012): Hydration of Portland cement with high replacement by siliceous fly ash. Cement and Concrete Research, 42, 1389-1400. doi: 10.1016/j.cemconres.2012.06.009

51. Abd El-Aziz M., Abd El-Aleem S., Heikal M., ElDidamony H. (2004): Effect of Polycarboxylate on Rice Husk Ash Pozzolanic Cement. Sil. Ind., 69, 73-84.

52. Legrand C., Wirquin E. (1994): Study of the strength of very young concrete as afunction of the amount of hydrates formed-influence of superplasticizer. Material Structure, 27, 106-109. doi: 10.1007/BF02472828

53. Hou P., Kawashima S., Kong D., Corr D.J., Qian J., Shah S.P. (2013): Modification effects of colloidal nano- $\mathrm{SiO}_{2}$ on cement hydration and its gel property. Composites Part B: Engineering, 45, (2013), 440-8. doi: 10.1016/j. compositesb.2012.05.056

54. Zhang M.H, Li H. (2011): Pore structure and chloride permeability of concrete containing nano-particles for pavement. Construction and Building Material, 25, 608-616. doi: 10.1016/j.conbuildmat.2010.07.032

55. Hosseini P., Booshehrian A., Madari A. (2011): Developing concrete recycling strategies by utilization of nano- $\mathrm{SiO}_{2}$ particles. Waste Biomass Valorization, 2, 347-355. doi: 10.1007/s12649-011-9071-9

56. Björnström J., Martinelli A., Matic A., Börjesson L., Panas I. (2004): Accelerating effects of colloidal nano-silica for beneficial calcium-silicate-hydrate formation in cement. Chemical Physics Letters, 392, 242-248. doi: 10.1016/j. cplett.2004.05.071

57. Ji T. (2005): Preliminary study on the water permeability and microstructure of concrete incorporating nano- $\mathrm{SiO}_{2}$. Cement and Concrete Research, 35, 1943-1947. doi: 10.1016/j.cemconres.2005.07.004

58. Heikal M., Abdel-Gawwad H.A., Ababneh F.A. (2018): Positive impact performance of hybrid effect of nanoclay and silica nano-particles on composite cements. Construction and Building Materials, 190, 508-516. doi: 10.1016/j.conbuildmat.2018.09.163

59. El-Didamony H., Amer A.A., Helmy I.M., Mostafa K. (1996): Durability of sulphate resisting slag blended cements and mortars in sea water. Indian Journal of Engineering and Materials Sciences, 3, 35-40. 
60. Esteves L.P. (2011): On the hydration of water-entrained cement - silica systems combined SEM, XRD and thermal analysis in cement pastes. Thermochimica Acta, 518, 27-35. doi: 10.1016/j.tca.2011.02.003

61. Wongkeo W., Chaipanich A. (2010): Compressive strength, microstructure and thermal analysis of autoclaved and air cured structural lightweight concrete made with coal bottom ash and silica fume. Material Science Engineering, 527, 3676-3684. doi: 10.1016/j.msea.2010.01.089

62. Vedalakshmi R. (2003): Quantification of hydrated cement products of blended cement in low and medium strength concrete using TG and DTG technique. Thermochimica Acta, 407, 49-60. doi: 10.1016/S0040-6031(03)00286-7

63. Deschner F., Lothenbach B., Winnefeld F., Neubauer J. (2013): Effect of temperature on the hydration of Portland cement blended with fly ash. Cement and Concrete Research, 52, 169-181. doi: 10.1016/j.cemconres.2013.07.006

64. Colston S.L., Connor D., Barnesm P. (2000): Functional micro-concrete: The incorporation of zeolites and inorganic nano-particles into cement micro-structures. Journal of Materials Science Letters, 19, 1085-1088. 